\title{
Inverted Sandwich Arene Complexes of Uranium
}

Stephen T. Liddle*

School of Chemistry, University of Nottingham, University Park, Nottingham, NG7 2RD, UK.

*Email: stephen.liddle@nottingham.ac.uk

\section{Contents}

Keywords

Abstract

1. Introduction

1.1. $\mathrm{C}_{4}$-Ligands

1.2. $\mathrm{C}_{5}$-Ligands

1.3. $\mathrm{C}_{6}$-Ligands

1.4. $\mathrm{C}_{7}$-Ligands

1.5. $\mathrm{C}_{8}$-Ligands

1.6. Uranium

2. Cyclobutadienyl Complexes of Uranium

2.1. Cyclobutadienyl

2.2. Diphosphacyclobutadienyl

3. Cyclopentadienyl Complexes of Uranium

3.1. The Paucity of Inverse Sandwich Cyclopentadienyl Complexes

4. Arene Complexes of Uranium

4.1. Diuranium(III) Arenes

4.2. Diuranium(V) Arenes

5. Cycloheptatrienyl Complexes of Uranium

6. Cyclooctatetraenyl Complexes of Uranium

7. Summary and Outlook

Acknowledgements

References 


\title{
Keywords
}

uranium, cyclobutadienyl, cyclopentadienyl, arene, cycloheptatrienyl, cyclooctatetraenyl

\begin{abstract}
The chemistry of arene complexes of uranium has for over half a century been an important facet of organoactinide chemistry. Within this extensive and burgeoning field, in the past two decades inverted sandwich complexes have emerged incorporating cyclobutadienyl, arene, cycloheptatrienyl, and cyclooctatetraenyl ligands. Herein, the field is reviewed with an emphasis on well-defined molecular species that have been unambiguously characterised by X-ray crystallography.
\end{abstract}

\section{Introduction}

Since the report of the synthesis of $\left[\mathrm{U}\left(\eta^{5}-\mathrm{C}_{5} \mathrm{H}_{5}\right)_{3} \mathrm{Cl}\right]$ in 1956 [1], and its structural characterisation in 1965 [2], the chemistry of arene-derived complexes of uranium (where arene is defined as a cyclic hydrocarbon with alternating single and double bonds which includes heteroarenes as a sub-class), and more broadly speaking of the actinides, has developed over the last half a century to become an important facet of non-aqueous uranium chemistry [3]. Such organometallics are of interest not only from a fundamental perspective of understanding the bonding of uranium to organometallic ligands, but also because of the potentially novel reactivity that such complexes might underpin [4-12]. Regarding the bonding aspects, the nature (5f vs $6 \mathrm{~d}$ orbital participation; $\sigma, \pi$, or $\delta$-bonding) and extent of any covalency in uraniumligand linkage bonding is still widely debated and seems to vary depending on the nature of the ligand and oxidation state of uranium so studies of the bonding of varying sizes of arene ligands to uranium can be very instructive. Cyclopentadienyl/metallocene derivatives of uranium are legion, and sandwich molecules such as uranocene, $\left[\mathrm{U}\left(\eta^{8}-\mathrm{C}_{8} \mathrm{H}_{8}\right)_{2}\right]$ [13-15], represent major milestones in organoactinide chemistry because of the profound implications the bonding schemes of such molecules have had on our understanding of chemical bonding. An interesting and burgeoning category of arene complexes of uranium is that of inverted sandwich complexes where the arene bridges two uranium centres. Examples of these complexes now include cyclobutadienyl, benzene-derivatives, cycloheptatrienyl, and cyclooctatetraenyl derivatives. Herein, the field is reviewed with an emphasis on well- 
defined molecular species that have been unambiguously characterised by X-ray crystallography. In reaction schemes specific conditions of reactions are not given unless they are of major significance and the reader is referred to the individual references for further experimental details. In discussions of uranium-ring distances the ranges of $\mathrm{U}-\mathrm{C}$ bond lengths are given rather than $\mathrm{U}$-centroid distances; not all $\mathrm{U}$ ring interactions are symmetrical so U-centroid distances can be skewed whereas the range of U-C distances arguably gives a more representative picture of the U-C interactions. This Review is structured by increasing size of the bridging arene, and within each class of arene in chronological order so the reader may appreciate the historical development of each area.

Before the various classes of inverted sandwich arene complexes of uranium are described, it is instructive to overview the nature of arene ligands and the character of their potential interactions with uranium, Figure 1. In all instances, from the formal perspective of complex construction, a neutral arene can be combined with neutral uranium fragments with a net sharing of some valence electrons to construct bonding interactions. For transition metals, the bonding is often quite covalent so considerations of any electron transfer are to some extent formal. However, although uranium does engage in some covalent bonding these interactions are predominantly electrostatic so it is convenient to consider formal electron transfer from uranium to arene fragments to generate formal anionic ligand species bonded to a cationic metal fragment. This is in much the same way that sodium cyclopentadienyl is intuitively considered to be a sodium cation paired with a $6 \pi$-electron cyclopentadienyl anion rather than a neutral sodium paired with a $5 \pi$-electron radical cyclopentadiene species. An important aspect to appreciate is that arenes usually principally donate electron density to transition metal centres with some backbonding, and hence they are usually, but not always, bound to only one metal. For uranium, a formal electron transfer from metal to ligand usually occurs, and thus the arene becomes an electron rich, predominantly electron acceptor moiety and so bridging coordination modes, the subject of this Review, are much more common than in the d-block.

\section{1. $C_{4}$-Ligands}


The $D_{4 \mathrm{~h}}$ cyclobutadiene presents a $\pi$ molecular orbital manifold of $\psi$ orbitals 1-4 of $a$, $e$, and $b$ symmetry, respectively. The $a$-orbital is suited to $\sigma$-type bonding, the e-set to $\pi$-bonding, and the $b$-orbital to $\delta$-bonding. Square butadiene is a diradical according to Hund's rule, and in the absence of metal-stabilisation would be expected to distort to the rectangular singlet form. Alternatively, two-electron reduction to cyclobutadienyl affords a $6 \pi$-electron aromatic system. Although $\delta$-bonding of cyclobutadienyl is in principle possible from a symmetry perspective, in practice the vacant $\psi_{4}$ orbital is usually energetically too high-lying to effectively engage in $\delta$-bonding and the small ring size may result in poor $\delta$-orbital overlap with metal-based frontier orbitals so $\sigma$ and $\pi$-bonding would be expected to dominate for this system, as is the case with transition metals.

\section{2. $C_{5}$-Ligands}

Cyclopentadiene, $\mathrm{C}_{5}$, exhibits a $\pi$ molecular orbital manifold of $\psi$ orbitals $1-5$ of $a$ and two pairs of $e$ symmetry, respectively. As for $\mathrm{C}_{4}$, these are suitable for $\sigma, \pi$, and $\delta$-type bonding interactions. Cyclopentadiene, a $5 \pi$-electron radical readily accepts an electron to become an $6 \pi$-electron aromatic cyclopentadienyl system that has an extensive literature regarding bonding to uranium. However, the $D_{5 \mathrm{~h}}$ cyclopentadienyl monoanion is not particularly electron rich, and so there are few precedents of inverted sandwich complexes of cyclopentadienyl in the f-block. Like $\mathrm{C}_{4}$, $\sigma$ - and $\pi$ bonding modes are anticipated to dominate and although $\delta$-bonding is more favourable than for $\mathrm{C}_{4}$, angular constraints often result in weak $\delta$-bonding of the empty $\psi_{4}$ and $\psi_{5}$ orbitals to metal centres.

\section{3. $C_{6}$-Ligands}

The $D_{6 \mathrm{~h}} \mathrm{C}_{6}$-arene scaffold, is a neutral $6 \pi$-electron manifold of $\psi$ orbitals 1-6 of $a$, two $e$ pairs, and $b$ symmetry. These frontier orbitals may be classified as being suitable for $\sigma\left(\psi_{1}\right), \pi\left(\psi_{2}\right.$ and $\left.\psi_{3}\right)$, and $\delta\left(\psi_{4}\right.$ and $\left.\psi_{5}\right)$ bonding combinations, with in principle the $\psi_{6}$ being suited to $\phi$ bonding, the latter of which is a bonding mode unique to actinides and invoked for uranium in the bonding scheme of uranocene [13]. Although in principle $\mathrm{C}_{6}$ aromatics do not require the addition of any electrons to satisfy Huckel's $4 n+2 \pi$-electron rule, the strongly reducing nature of uranium(III) combined with the relatively low-lying $\psi_{4}$ and $\psi_{5}$ orbitals often results in the 
generation of arene rings with variable levels of reduction - for diuranium derivatives formal two-electron reduction is now relatively common, and formal four-electron reduction, which generates a $10 \pi$-electron system that satisfies Huckel's $4 n+2 \pi$ electron rule, is also now known. However, it is germane to reiterate that these situations are accompanied by extensive $\delta$-bonding, which tends to dominate over $\sigma$ and $\pi$ interactions because of better spatial overlap and energetically matched frontier orbitals ( $c f$ bonding schemes of metallocenes versus bis-benzene metal complexes), so classifying formal charges and electron sharing/transfer becomes something of a nebulous endeavour.

\section{4. $C_{7}$-Ligands}

The cycloheptatriene $\mathrm{C}_{7}$ framework is an interesting carbocycle - removal of hydride from the parent $\mathrm{C}_{7} \mathrm{H}_{8}$ molecule generates a $6 \pi$-electron monocation, whereas removal of a proton generates a $8 \pi$-electron monoanion, which if reduced by two electrons

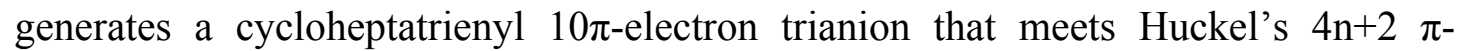
electron rule. In the context of uranium chemistry, cycloheptatrienyl is best regarded as a $10 \pi$-electron trianion. The $\pi$ molecular orbital manifold of $D_{7 \mathrm{~h}}$ cycloheptatrienyl follows a familiar pattern of $\psi$ orbitals $1-7$, of $a(\sigma)$, and three pairs of $e$ symmetry $(\pi$ then $\delta$ ), with the first five orbitals being most important from symmetry and energetic considerations with respect to bonding to metal centres.

\section{5. $C_{8}$-Ligands}

The $\mathrm{C}_{8}$ cyclooctatetraene exhibits a $\pi$ molecular orbital manifold of $\psi$ orbitals 1-8 of $a$, three $e$ pairs, then $b$ symmetry orbitals. Analogously to $\mathrm{C}_{7}$ the top three $\psi$ orbital combinations can be essentially ignored in the treatment of the bonding of $\mathrm{C}_{8}$, with the remaining orbitals being utilised in $\sigma\left(\psi_{1}\right), \pi\left(\psi_{2}\right.$ and $\left.\psi_{3}\right)$, and $\delta\left(\psi_{4}\right.$ and $\left.\psi_{5}\right)$ bonding combinations. Cyclooctatetraene exhibits four localised double bonds in its 'bath-tub' $8 \pi$-electron system, but two-electron reduction affords the $D_{8 \mathrm{~h}} 10 \pi$-electron planar aromatic dianion. There are various debates over the name of the resulting dianion [15], but for the sake of simplicity and internal consistency of this Review we shall refer to the dianion as cyclooctatetraenyl. Like $\mathrm{C}_{6}$ and $\mathrm{C}_{7}$ carbocycles, because of the relative size-matching and energies of the frontier orbitals, $\delta$-bonding of cyclooctatetraenyl to uranium would be expected to be the dominant bonding motif 
although this might be anticipated to be not as well matched as for $\mathrm{C}_{6}$ since the $\mathrm{C}_{8}$ ring is large and can be considered to be past the optimum point for interactions with metal-based frontier orbitals.

\subsection{Uranium}

Starting with a $[R n] 5 f^{3} 6 d^{1} 7 s^{2}$ electronic configuration, uranium ionises by loss of $7 \mathrm{~s}$ and $6 \mathrm{~d}$ electrons first followed by $5 \mathrm{f}$ electrons depending on the final oxidation state of uranium. Since the seven uranium valence 5 f orbitals adopt $m_{l}$ values of $0,1,2$, and 3 , these atomic orbitals are well suited to partake in $\sigma, \pi, \delta$, and $\phi$ bonding, respectively, if appropriately orientated with respect to ligand frontier orbitals. Additionally, due to relativistic effects the $5 \mathrm{f}$ and $6 \mathrm{~d}$ orbitals are of similar energies and thus can in principle hybridise and, most importantly, extend out from the atomic core into the valence region. The result is that the valence $5 \mathrm{f}$ and $6 \mathrm{~d}$ orbitals of uranium can in principle straightforwardly engage to some extent in covalent bonding to arene ligands, but the extent and exact nature of these interactions is not easy to predict a priori and electrostatic interactions still dominate the bonding of uranium.

\section{Cyclobutadienyl Complexes of Uranium}

\subsection{Cyclobutadienyl}

Although d-block cyclobutadienyl complexes have been known for decades [16], the first example of a uranium cyclobutadienyl complex, indeed the first cyclobutadienyl complex of any f-block metal, was only reported in 2013, Scheme 1 [17]. Treatment of the diuranium $(\mathrm{V})$ toluene tetraanion complex $\left[\left\{\mathrm{U}\left(\mathrm{Ts}^{\mathrm{Xy}}\right)\right\}_{2}\left(\mu: \eta^{6}-\eta^{6}-\mathrm{C}_{6} \mathrm{H}_{5} \mathrm{Me}\right)\right][\mathbf{1}$, $\mathrm{Ts}^{\mathrm{Xy}}=\mathrm{HC}\left(\mathrm{SiMe}_{2} \mathrm{NC}_{6} \mathrm{H}_{3}-3,5-\mathrm{Me}_{2}\right)_{3}$, see Section 4.2. below for further details] [18] with two equivalents of diphenylacetylene afforded a complicated mixture, as assayed by ${ }^{1} \mathrm{H}$ NMR spectroscopy, which is postulated to contain an acyclic butadiene dianion derivative. Storage of solutions in hexane for 43 days afforded the cyclobutadienyl inverse sandwich complex $\left[\left\{\mathrm{U}\left(\mathrm{Ts}^{\mathrm{Xy}}\right)\right\}_{2}\left(\mu: \eta^{5}-\eta^{5}-\mathrm{C}_{4} \mathrm{Ph}_{4}\right)\right]$ (2) in low (20\%) but reproducible yield. Complex $\mathbf{2}$ is the product of a formal reductive $[2+2]$ cycloaddition reaction overall where two acetylene molecules are coupled then cyclised and reduced in a two-electron reduction process with concomitant reduction of uranium(V) to (IV) with the remaining two electrons from the toluene tetraanion. It is postulated that the acyclic butadiene dianion is formed first, and over time the 
barrier to cyclisation to form a strained four-membered ring is overcome by the aromatic stabilisation energy and the precipitation of $\mathbf{2}$ from non-polar solvent driving the equilibrium towards completion. The crystal structure of 2 (Figure 2) shows a dinuclear structure with a bridging and asymmetrically coordinated $\left\{\mathrm{C}_{4} \mathrm{Ph}_{4}\right\}^{2-}$ ring; each uranium interacts with the $\mathrm{C}_{4}$-ring but is skewed towards one edge and each uranium appears to be involved in an interaction to a phenyl ring ispo-carbon atom. The $\mathrm{U}_{-} \mathrm{C}_{\mathrm{ipso}}$ distances are 2.842(5) and 2.887(5) $\AA$, whereas the $\mathrm{U}-\mathrm{C}_{\text {ring }}$ bond lengths fall into two ranges of ca. 2.66 and $2.86 \AA$ reflecting the asymmetric coordination mode. This suggests that there may be some delocalisation of charge onto the phenyl rings, and ${ }^{1} \mathrm{H}$ NMR spectroscopic studies suggest that this binding mode is maintained in solution.

\subsection{Diphosphacyclobutadienyl}

One reason for the sluggish reaction of 1 with $\mathrm{PhCCPh}$ may be the lack of a dipole in the latter. To test this hypothesis the para-tolyl analogue of $\mathbf{1},\left[\left\{\mathrm{U}\left(\mathrm{Ts}^{\mathrm{Tol}}\right)\right\}_{2}\left(\mu: \eta^{6}-\eta^{6}-\right.\right.$ $\left.\left.\mathrm{C}_{6} \mathrm{H}_{5} \mathrm{Me}\right)\right]\left[3, \mathrm{Ts}^{\mathrm{Tol}}=\mathrm{HC}\left(\mathrm{SiMe}_{2} \mathrm{NC}_{6} \mathrm{H}_{4}-4-\mathrm{Me}\right)_{3}\right.$ ] [19] was treated with two equivalents of the polar phosphaalkyne $\mathrm{Bu}^{\mathrm{t}} \mathrm{CP}$ (note the isolelectronic relationship between $\mathrm{CR}$ and $P)$ to afford the diphosphacyclobutadienyl complex $\left[\left\{\mathrm{U}\left(\mathrm{Ts}^{\mathrm{Xy}}\right)\right\}_{2}\left(\mu: \eta^{4}-\eta^{4}-\right.\right.$ $\left.\mathrm{C}_{2} \mathrm{P}_{2} \mathrm{Bu}_{2}^{\mathrm{t}}\right)$ ] (4) in $69 \%$ yield within 24 hours, Scheme 1. The solid state structure of 4 , Figure 3, revealed a symmetrical binding mode of the $\left\{\mathrm{C}_{2} \mathrm{P}_{2} \mathrm{Bu}_{2}^{\mathrm{t}}\right\}^{2-}$ ligand to the two uranium centres, presumably as a result of replacing electron rich phenyl rings with tert-butyl groups. The U-P and U-C distances in 4 span the ranges 2.9081(5)3.0358(5) $\AA$ and 2.778(2)-2.981(2) $\AA$, respectively, and agree well with distances observed in uranium $\eta^{5}$-phospholide complexes [20].

The spectroscopic and magnetic data for $\mathbf{2}$ and $\mathbf{4}$ are consistent with uranium(IV) centres. Density Functional Theory calculations on $\mathbf{2}$ and $\mathbf{4}$ are consistent with the oxidation state assignments returning spin densities of $\sim 2$ electrons at uranium and arene charges of $\sim-2.4$ to -2.8 , respectively. The calculations revealed that the bonding is principally electrostatic, but a non-negligible covalent component is present. Within this covalent contribution to the bonding description what emerges is that $\pi$-bonding between the arene $\psi_{2}$ and $\psi_{3}$ orbitals and uranium orbitals of 
predominantly $5 \mathrm{f}$ parentage represents the dominant bonding component. Although $\delta$ bonding combinations could be identified for $\mathbf{2}$ and $\mathbf{4}$ these are clearly of limited significance as would be expected. The dominance of $5 \mathrm{f}$ orbitals in the bonding may reflect the angular constraints of bonding to a four-membered ring since in uranocene larger $6 \mathrm{~d}$ orbital contributions are invoked in the bonding model of uranium to the spatially larger $\mathrm{C}_{8}$-ring [13].

No tractable product could be isolated from the reactions of $\mathbf{3}$ with $\mathrm{PhCCPh}$ or $\mathbf{1}$ with $\mathrm{Bu}^{\mathrm{t}} \mathrm{CP}$. The conclusion from this is that sterics are clearly an important factor in constructing and stabilising such linkages, either in terms of steric overload destabilising the resultant complexes or a lack of steric protection allowing facile decomposition routes.

\section{Cyclopentadienyl Complexes of Uranium}

\subsection{The Paucity of Inverse Sandwich Cyclopentadienyl Complexes}

There are numerous examples of cyclopentadienyl uranium complexes but these have been comprehensively reviewed recently [21] and they lie outside of the scope of this Review. Where inverted sandwich complexes are concerned, there are no examples of a cyclopentadienyl ring bridging two uranium centres. Indeed, more generally the majority of examples of f-block complexes exhibiting $\mu: \eta^{5}-\eta^{5}$-cyclopentadienyl rings are lanthanide complexes, for example in polymeric $\left[\mathrm{Y}\left(\eta^{5}-\mathrm{C}_{5} \mathrm{H}_{4} \mathrm{Me}\right)_{3}(\mathrm{THF})\right]$ [22], and they are relatively rare. The one notable exception, which is the closest congener to a uranium complex, is the hexanuclear thorium complex $\left[\left\{(\operatorname{Th})_{2}\left(\operatorname{OPr}^{\mathrm{i}}\right)_{7}\left(\mu: \eta^{5}-\eta^{5}-\right.\right.\right.$ $\left.\left.\mathrm{C}_{5} \mathrm{H}_{5}\right)\right\}_{3}$ ] [23]. As discussed above, the origin of this paucity of uranium inverted sandwich cyclopentadienyl complexes may be the relatively low electron richness of the cyclopentadienyl monoanion, which is less of an issue where the more ionic thorium and lanthanide metals are concerned, or it may just be that the right ligand combination to support a cyclopentadienyl ligand bridging uranium centres has not yet been combined.

\section{Arene Complexes of Uranium}

\subsection{Diuranium(III) Arenes}

Although uranium $\mathrm{C}_{6}$-arene complexes have been known since 1971 [24-35], it was not until 2000 that the first diuranium inverted $\mathrm{C}_{6}$-arene sandwich complexes were 
reported. Treatment of $\left[\mathrm{U}(\mathrm{I})(\mathrm{L})_{3}\right]\left[5, \mathrm{~L}=\mathrm{N}(\mathrm{R})\left(\mathrm{C}_{6} \mathrm{H}_{3}-3,5-\mathrm{Me}_{2}\right) ; \mathrm{R}=\mathrm{Bu}^{\mathrm{t}}\right.$, adamantyl] with excess $\mathrm{KC}_{8}$ in toluene afforded the sandwich complexes $\left[\left\{\mathrm{U}(\mathrm{L})_{2}\right\}_{2}\left(\mu: \eta^{6}-\eta^{6}-\right.\right.$ $\left.\left.\mathrm{C}_{6} \mathrm{H}_{5} \mathrm{Me}\right)\right](\mathbf{6 a} / \mathbf{b})$ in $40 \%$ isolated yield with concomitant elimination of $\mathrm{KI}$ and one amide ligand per uranium, the latter presumably extruded as its potassium salt, Scheme 2 [36]. The structure of $\mathbf{6 b}$ was determined by X-ray crystallography, Figure 4 , which revealed a toluene molecule sandwiched between the two uranium centres. The toluene C-C distances were only elongated by $\sim 0.04 \AA$ compared to free toluene but the ring is slightly puckered. The U-C distances in $\mathbf{6 b}$ are notably short at 2.593(9) $\AA$ (av.), which compares to a mean U-C distance of 2.93(2) $\AA$ in $\left[U\left(\eta^{6}-\right.\right.$ $\left.\mathrm{C}_{6} \mathrm{Me}_{6}\right)\left(\mathrm{BH}_{4}\right)_{3}$ ] [30], and this hints at strong uranium-arene interactions in $\mathbf{6 a} / \mathbf{b}$. The assignment of formal oxidation states for the uranium centres in $\mathbf{6 a} / \mathbf{b}$ posed a question since if the toluene was considered to be neutral then uranium(II) centres would be invoked for charge neutrality. On the other hand uranium(III) centres would require a toluene dianion and at the upper extreme a toluene tetraanion with uranium(IV) centres could be proposed. As has been subsequently demonstrated (see below), this complex is best formulated as containing uranium(III) centres, but importantly it acts as a divalent uranium synthon delivering four electrons to suitable substrates. For example, 6a reacts with two equivalents of $\mathrm{PhSSPh}$ to afford $\left[\left\{\mathrm{U}(\mathrm{L})_{2}(\mathrm{SPh})(\mu-\mathrm{SPh})\right\}_{2}\right]$ (7) in $74 \%$ yield or one equivalent of $\mathrm{PhNNPh}$ to give $\left[\left\{\mathrm{U}(\mathrm{L})_{2}(\mu-\mathrm{NPh})\right\}_{2}\right](\mathbf{8})$ in $67 \%$ yield, Scheme 2. The unrestricted calculated structure of $\mathbf{6 a} / \mathbf{b}$, using the simplified model $\left[\left\{\mathrm{U}\left(\mathrm{NH}_{2}\right)_{2}\right\}_{2}\left(\mu: \eta^{6}-\eta^{6}-\mathrm{C}_{6} \mathrm{H}_{6}\right)\right]$ constrained to $D_{2}$ symmetry returned, in the $\alpha$ spin manifold, the four most energetic electrons as being non-bonding 5 f-electrons, with the next four electrons ( $\alpha$ - and $\beta$-spin) being stabilised in covalent $\delta$-bonding interactions between uranium $5 \mathrm{f}$ and $6 \mathrm{~d}$ hybrid orbitals and the benzene LUMOs.

Two years after the report of $\mathbf{6 a} / \mathbf{b}$, the synthesis of the ketimide (ketimide $=$ $\left.\mathrm{RR}^{\prime} \mathrm{C}=\mathrm{N}^{-}\right)$inverted sandwich naphthalene complexes $\left[\left\{\mathrm{U}\left(\mathrm{NCBu}{ }^{\mathrm{t}} \mathrm{Mes}\right)_{3}\right\}_{2}\left(\mu: \eta^{6}-\eta^{6}-\right.\right.$ $\left.\left.\mathrm{C}_{10} \mathrm{H}_{8}\right)(\mathrm{M})_{2}\right](\mathrm{M}=\mathrm{K}, 9 \mathbf{9 a}, 60 \%$ yield; $\mathrm{M}=\mathrm{Na}, \mathbf{9 b}, 40 \%$ yield; Mes $=2,4,6-$ trimethylphenyl) were reported by the reduction of the uranium tris(ketimide) complex $\left[\mathrm{U}\left(\mathrm{NCBu}^{\mathrm{t}} \mathrm{Mes}\right)_{3}(\mathrm{I})(\mathrm{DME})\right]$ with potassium graphite or sodium mirror, respectively, Scheme 3 [37]. The synthesis of $9 \mathbf{a} / \mathbf{b}$ contrasts to that of $6 \mathbf{a} / \mathbf{b}$ because in the former all three ketimide ligands are retained at uranium whereas in the latter an amide ligand is eliminated during the synthesis. The consequence of this is that whereas $\mathbf{6 a} / \mathbf{b}$ are neutral, $9 \mathbf{a} / \mathbf{b}$ are dianionic and incorporate two alkali metals to 
attain charge neutrality. The $\mu: \eta^{6}-\eta^{6}$-bridging mode of the naphthalene is notable since where this moiety bridges electropositive metals it usually does so by each sixmembered ring bonding to a different metal on each side of the naphthalene rather than on each side of the same ring. In 9a, Figure 5, the U-C distances span the range $2.565(11)$ to $2.749(10) \AA$, which is similar to $\mathbf{6 b}$, and the longer U-C interactions involve the carbon atoms fusing the two six-membered rings of naphthalene together which do not make any appreciable orbital contribution to the LUMO of naphthalene. Complexes $\mathbf{9 a} / \mathbf{b}$ are competent reagents for multi-electron reductions for the preparation of cyclooctatetraenyl complexes (see Section 6 below).

In 2004 inverted sandwich benzene complexes of uranium were reported prepared via sterically induced reduction chemistry [38]. The uranium complex $\left[\mathrm{U}\left(\eta^{5}-\mathrm{C}_{5} \mathrm{Me}_{5}\right)_{3}\right]$ reacts with potassium graphite in the presence of benzene to eliminate $\left[\mathrm{K}\left(\eta^{5}-\mathrm{C}_{5} \mathrm{Me}_{5}\right)\right]$ and generate $\left[\left\{U\left(\eta^{5}-C_{5} M_{5}\right)_{2}\right\}_{2}\left(\mu: \eta^{6}-\eta^{6}-C_{6} \mathrm{H}_{6}\right)\right](\mathbf{1 0})$ in $90 \%$ isolated yield, Scheme 4. Alternatively, 10 could be prepared from $\left[\mathrm{U}\left(\eta^{5}-\mathrm{C}_{5} \mathrm{Me}_{5}\right)_{2}\left(\mathrm{BPh}_{4}\right)\right]$ and potassium-18crown- 6 in the presence of benzene in $82 \%$ isolated yield. The crystal structure of $\mathbf{1 0}$, Figure 6, reveals a benzene ring sandwiched between two bispentamethylcyclopentadienyl uranium fragments. Interestingly, although the coordinated six-membered ring in 9a is essentially planar, the benzene ring in $\mathbf{1 0}$ is puckered and adopts a shallow boat conformation with two fold angles of 1.5 and $18.0^{\circ}$; in these complexes the potential energy surface of the conformation of the arene would be expected to be quite shallow. The $\mathrm{C}-\mathrm{C}$ bond lengths in $\mathbf{1 0}$ are indistinguishable from those in free benzene and the U-C bond lengths span a wide range of 2.51(1) to 2.73(1) $\AA$. Complex 10, whilst presumably presenting a less sterically demanding ligand set than three pentamethylcyclopentadienyl rings, is still clearly sterically encumbered as evidenced by its reaction with $\left[\mathrm{K}\left\{\mathrm{N}\left(\mathrm{SiMe}_{3}\right)_{2}\right\}\right]$ to produce the mixed amide-cyclopentadienyl benzene inverse sandwich complex $\left[\left\{\mathrm{U}\left(\eta^{5}-\mathrm{C}_{5} \mathrm{Me}_{5}\right)\left[\mathrm{N}\left(\mathrm{SiMe}_{3}\right)_{2}\right]\right\}_{2}\left(\mu: \eta^{6}-\eta^{6}-\mathrm{C}_{6} \mathrm{H}_{6}\right)\right](\mathbf{1 1})$ in $89 \%$ isolated yield. In contrast to 10, the coordinated benzene ring in $\mathbf{1 1}$ adopts a shallow chair conformation, Figure 7, with two identical fold angles of $7.2^{\circ}$ due to the ring residing over a crystallographic inversion centre, and the C-C distances (1.449(4)-1.458(4) $\AA$ ) are slightly elongated compared to free benzene (1.39 $\AA$ ). The U-C distances span the range 2.559(3) to 2.631(3) $\AA$, which is a relatively tight range reflecting the minor distortion from planarity of the benzene ring. 
Although room temperature magnetic and optical spectroscopy experiments on $\mathbf{1 0}$ could not conclusively support one formal bonding and oxidation state description over any other from the uranium(II)-neutral arene to uranium(IV)-arene 4- extremes, the observed U-C bond lengths support a double reduction of benzene when compared to clear-cut neutral arene to uranium bond lengths which average $2.93 \AA$. Consequently, arene exchange reactions at $\mathbf{1 0}$ were investigated. If the arene is largely neutral then substituted arenes should straightforwardly displace benzene since they are more basic in a Lewis sense. If on the other hand the arene carries charge then arenes that are better $\pi$-acceptors will displace more substituted, electron rich arenes. Thus, the benzene complex $\mathbf{1 0}$ is formed even when prepared in bulk toluene, deuterated benzene displaces benzene, and benzene displaces para-xylene from the para-xylene analogue of $\mathbf{1 0}\left(\left[\left\{\mathrm{U}\left(\eta^{5}-\mathrm{C}_{5} \mathrm{Me}_{5}\right)_{2}\right\}_{2}\left(\mu: \eta^{6}-\eta^{6}-\mathrm{C}_{6} \mathrm{H}_{4}-1,4-\mathrm{Me}_{2}\right)\right] \quad\right.$ (12), prepared from $\left[\mathrm{U}\left(\eta^{5}-\mathrm{C}_{5} \mathrm{Me}_{5}\right)_{3}\right]$, potassium graphite, and para-xylene) to give $\mathbf{1 0}$, Scheme 4. A competition experiment where $\left[\mathrm{U}\left(\eta^{5}-\mathrm{C}_{5} \mathrm{Me}_{5}\right)_{3}\right]$ was reduced by potassium graphite in the presence of benzene and para-xylene afforded $\mathbf{1 0}$ and $\mathbf{1 2}$ in a 3:1 ratio. Multi-electron redox chemistry is also exhibited by $\mathbf{1 0}$ in the preparation of cyclooctatetraenyl complexes (see Section 6 below).

The electronic structure of $\mathbf{1 0}$ was probed by theoretical calculations. As for the simplified model of $\mathbf{6 a} / \mathbf{b}$, the calculations reveal four unpaired $\alpha$-spin electrons of $\mathrm{f}$ parentage, followed by two $\delta$-bonding combinations that are $\alpha$ - and $\beta$-spin occupied. The latter are clearly identifiable as involving predominantly f-based orbitals with the $\psi_{4}$ and $\psi_{5}$ orbitals of benzene. The calculations reveal charges of -2.21 and -2.39 on the arenes in $\mathbf{1 0}$ and $\mathbf{1 1}$, consistent with double reduction as expected. Thus, the calculations suggest a uranium(III)-arene 2- formulation as most appropriate for these systems. Although the quintet 'high-spin' form of $\mathbf{1 0}$ was initially calculated, broken symmetry calculations suggest that the anti-ferromagnetically coupled 'low-spin' form lies $9.6 \mathrm{~kJ} \mathrm{~mol}^{-1}$ lower in energy; however, given the inherent error of such calculations, and their scalar nature, all that can be stated with certainty is that there are different spin-states in close energetic proximity. Analogous broken symmetry calculations were attempted for $\mathbf{1 1}$ but could not be converged, which highlights the 
real practical difficulties in probing the electronic structure of such systems where multiple spin states are close in energy and possibly multi-configurational in nature.

Following the initial report establishing of the synthesis, characterisation, and electronic structure of 10, a reactivity study was reported in 2009 [39]. Complex 10, known to exchange a pentamethylcyclopentadienyl ligand for a bulky amide to give 11, engages in a wide range of ligand exchange reactions. For example, $\left[\mathrm{K}\left(\mathrm{OC}_{6} \mathrm{H}_{2}-\right.\right.$ 2,6-But $-4-\mathrm{Me})]$ and $\left[\mathrm{Li}\left\{\mathrm{CH}\left(\mathrm{SiMe}_{3}\right)_{2}\right\}\right]$ react with 10 to afford $\left[\left\{\mathrm{U}\left(\eta^{5}-\mathrm{C}_{5} \mathrm{Me}_{5}\right)\left(\mathrm{OC}_{6} \mathrm{H}_{2}-\right.\right.\right.$ $\left.\left.\left.2,6-\mathrm{Bu}^{\mathrm{t}}-4-\mathrm{Me}\right)\right\}_{2}\left(\mu: \eta^{6}-\eta^{6}-\mathrm{C}_{6} \mathrm{H}_{6}\right)\right] \quad(\mathbf{1 3}, \quad 76 \%$ isolated yield $)$ and $\left[\left\{\mathrm{U}\left(\eta^{5}-\right.\right.\right.$ $\left.\left.\left.\mathrm{C}_{5} \mathrm{Me}_{5}\right)\left[\mathrm{CH}\left(\mathrm{SiMe}_{3}\right)_{2}\right]\right\}_{2}\left(\mu: \eta^{6}-\eta^{6}-\mathrm{C}_{6} \mathrm{H}_{6}\right)\right](\mathbf{1 4}, 73 \%$ isolated yield $)$, respectively, Scheme 5 , which are structurally very similar to $\mathbf{1 1}$. Complex $\mathbf{1 0}$ also reacts with the lithium amidinate $\left.\left[\mathrm{Li}\left\{\mathrm{MeC}(\mathrm{NPr})_{2}^{\mathrm{i}}\right)_{2}\right\}\right]$ to afford $\left[\left\{\mathrm{U}\left(\eta^{5}-\mathrm{C}_{5} \mathrm{Me}_{5}\right)\left[\mathrm{MeC}\left(\mathrm{NPr}^{\mathrm{i}}\right)_{2}\right]\right\}_{2}\left(\mu: \eta^{6}-\eta^{6}-\mathrm{C}_{6} \mathrm{H}_{6}\right)\right]$ (15, 86\% isolated yield), Scheme 5, but this complex was not structurally characterised as suitable crystalline material could not be obtained. The solid state structures of 11 and $\mathbf{1 4}$ both exhibit shallow chair conformations, in contrast to the shallow boat conformation observed in $\mathbf{1 0}$. The X-ray crystallographic data for $\mathbf{1 3}$ are poor and only allow for the confirmation of atomic connectivities, but the data for $\mathbf{1 4}$ were of good quality and revealed U-C distances over the narrow range 2.532(2) to 2.558(2) $\AA$. The benzene $\mathrm{C}-\mathrm{C}$ distances in $\mathbf{1 4}$ span the narrow range 1.454(3) to 1.461(3) $\AA$ and are indistinguishable to the corresponding values in 11. Complexes 11, 14, and 15 each exhibit multi-electron reduction chemistry to react with $\mathrm{C}_{8} \mathrm{H}_{8}$ to generate the mixed-sandwich complexes $\left[\mathrm{U}\left(\eta^{8}-\mathrm{C}_{8} \mathrm{H}_{8}\right)\left(\eta^{5}-\mathrm{C}_{5} \mathrm{Me}_{5}\right)(\mathrm{X})\right]\left[\mathrm{X}=\mathrm{N}\left(\mathrm{SiMe}_{3}\right)_{2}\right.$, 16; $\left.\mathrm{X}=\mathrm{CH}\left(\mathrm{SiMe}_{3}\right)_{2}, \mathbf{1 7} ; \mathrm{X}=\mathrm{MeC}\left(\mathrm{NPr}^{\mathrm{i}}\right)_{2}, \mathbf{1 8}\right]$ in yields of $50-77 \%$, Scheme 6 . The reactivity of adamantyl azide $\left(\mathrm{AdN}_{3}\right)$ towards 10, 11, 14, and 15 was also studied affording a variety of novel multi-electron redox products, Scheme 7. Complex $\mathbf{1 0}$ reacts with four equivalents of $\mathrm{AdN}_{3}$ to give the bis-imido complex $\left[\mathrm{U}\left(\eta^{5}\right.\right.$ $\left.\left.\mathrm{C}_{5} \mathrm{Me}_{5}\right)_{2}(\mathrm{NAd})_{2}\right](19)$ with loss of benzene and dinitrogen. In contrast, the reactions of 11 and 15 with $\mathrm{AdN}_{3}$ generate predominantly the bis-imido complexes $\left[\mathrm{U}\left(\eta^{5}\right.\right.$ $\left.\left.\mathrm{C}_{5} \mathrm{Me}_{5}\right)(\mathrm{NAd})_{2}(\mathrm{X})\right]\left[\mathrm{X}=\mathrm{N}\left(\mathrm{SiMe}_{3}\right)_{2}, \mathbf{2 0} ; \mathrm{X}=\mathrm{MeC}\left(\mathrm{NPr}^{\mathrm{i}}\right)_{2}, 21\right]$, respectively, with small $(<10 \%)$ quantities of $\mathbf{1 9}$, which is presumably formed by ligand redistribution reactions. The reactivity of $\mathbf{1 4}$ is considerably more complicated, perhaps reflecting the presence of the more reactive U-C $\sigma$-bonded hydrocarbyl group in $\mathbf{1 4}$ compared to the less reactive amide and amidinate groups of 11 and 15, yielding multi-product reactions with reactivity at the arene and ancillary substituent. Specifically, the 
reaction of 14 with $\mathrm{AdN}_{3}$ affords three products that could be identified by X-ray diffraction, in addition to other products, namely 19, $\left[\mathrm{U}\left(\eta^{5}-\right.\right.$ $\left.\left.\mathrm{C}_{5} \mathrm{Me}_{5}\right)(\mathrm{NAd})_{2}\left\{\mathrm{AdNNNCH}\left(\mathrm{SiMe}_{3}\right)_{2}\right\}\right]$ (22, the result of insertion of $\mathrm{AdN}_{3}$ into the U$\mathrm{C} \sigma$-bond), and $\left[\mathrm{U}\left(\eta^{5}-\mathrm{C}_{5} \mathrm{Me}_{5}\right)\left(\mu: \eta^{5}: \kappa^{1}-\mathrm{C}_{5} \mathrm{Me}_{4} \mathrm{CH}_{2} \mathrm{NAd}\right)(\mathrm{NAd})\right]$ (23, C-H activation of a methyl group).

Up to this point there were no dedicated reports on the magnetism of diuranium arene inverted sandwich complexes. However, 2011 saw the report of a complex supported by a bis(iminophosphorano)methanide-halide ligand set which exhibits single molecule magnet behaviour [40]. Reaction of the dilithio methanediide transfer reagent $\left[\mathrm{Li}_{2}\left(\mathrm{BIPM}^{\mathrm{TMS}}\right)\right]\left[\mathrm{BIPM}{ }^{\mathrm{TMS}}=\mathrm{C}\left(\mathrm{PPh}_{2} \mathrm{NSiMe}_{3}\right)_{2}\right]$ with $\left[\mathrm{U}(\mathrm{Cl})_{4}(\mathrm{THF})_{4}\right]$ afforded the uranium carbene complex $\left[\left\{\mathrm{U}\left(\mathrm{BIPM}^{\mathrm{TMS}}\right)(\mu-\mathrm{Cl})(\mathrm{Cl})(\mathrm{THF})\right\}_{2}\right]$, which can be converted to the solvent free iodide complex $\left[\left\{\mathrm{U}\left(\mathrm{BIPM}^{\mathrm{TMS}}\right)(\mu-\mathrm{I})(\mathrm{I})\right\}_{2}\right]$ by treatment with $\mathrm{Me}_{3} \mathrm{SiI}$. Reduction of the iodide carbene dimer with potassium graphite in a mixture of THF and toluene results in reproducible reduction of toluene and protonation of the carbene to afford the arene-methanide-iodide complex $\left[\left\{\mathrm{U}\left(\mathrm{BIPM}{ }^{\mathrm{TMS}}\right)(\mathrm{I})\right\}_{2}\left(\mu: \eta^{6}-\eta^{6}-\mathrm{C}_{6} \mathrm{H}_{5} \mathrm{Me}\right)\right](\mathbf{2 4})$ in $20 \%$ crystalline yield, Scheme 8 . The formulation was confirmed by the solid state structure, Figure 8 , and revealed a planar toluene aromatic ring with U-C distances ranging from 2.553(7) to 2.616(7) $\AA$ and toluene ring $\mathrm{C}-\mathrm{C}$ distances elongated $\sim 0.02 \AA$ compared to free-toluene. Powder samples of complex $\mathbf{2 4}$ exhibit slow relaxation of the magnetisation, as evidenced by maxima at a number of frequencies in the $\chi^{\prime \prime}$ vs temperature $(\mathrm{K})$ plot of the out-ofphase imaginary part of the a.c. susceptibility. This behaviour is maintained, although is considerably weaker, in frozen-solution samples [41]. Additionally, at $1.8 \mathrm{~K}$ magnetic hysteresis is observed with a clear opening of the hysteresis curve, but this collapses at zero field which is indicative of efficient quantum tunneling of the magnetisation. Taken together these phenomena are the hallmarks of single molecule magnetism. Interestingly, the question of whether the observed phenomena originate from poly- or single-ion behaviour is still unresolved. However, it is clear from theoretical calculations on $\mathbf{2 4}$, which broadly report the same conclusions as earlier theoretical treatments so will not be repeated here, that some degree of electronic communication mediated by $\delta$-bonds is in principle possible and most likely operating, but the $\chi \mathrm{T}$ vs $\mathrm{T}$ plot does not show any signs of superexchange. Complex 24 is 
unusual for a diuranium arene complex in that one of the anionic ancillary ligands is tridentate, and thus together with the iodide and arene ligands the individual magnetic anisotropy of the uranium(III) ions should be enhanced due to an asymmetric crystal field. Complex 24 appears to exhibit a unique electronic environment for diuranium arene complexes which becomes apparent when the near infra red (NIR) region is inspected. In this region $\mathrm{f} \rightarrow \mathrm{f}$ transitions are expected, and since they are Laporte forbidden would be anticipated to exhibit relatively low extinction coefficients of $<200 \mathrm{M}^{-1} \mathrm{~cm}^{-1}$. However, the NIR region of the electronic absorption spectrum of $\mathbf{2 4}$ exhibits transitions with extinction coefficients of $\sim 4000 \mathrm{M}^{-1} \mathrm{~cm}^{-1}$. These transitions can be assigned to the ${ }^{4}$ I multiplet, but whilst intensity-stealing can be invoked to explain in part the incredible intensities of these transitions [42], this cannot account for all the observed intensities or their magnitudes. Thus, there are clear indications that uranium-uranium communication may be operating in complex $\mathbf{2 4}$, but this is not yet unequivocally confirmed. However, it is clear that combining the diuranium arene motif with certain ligands can foster single molecule magnetism.

In the same year as the report of $\mathbf{2 4}$, a diuranium arene complex supported by a ferrocene diamide ligand was reported and its use in assembling a supramolecular square demonstrated, Scheme 9 [43]. Reduction of $\left[\mathrm{U}\left(\mathrm{NN}^{\mathrm{fc}}\right)(\mathrm{I})_{2}(\mathrm{THF})\right]\left[\mathrm{NN}^{\mathrm{fc}}=\mathrm{Fe}\left(\eta^{5}-\right.\right.$ $\left.\mathrm{C}_{5} \mathrm{H}_{4} \mathrm{NSiMe}_{2} \mathrm{Bu}^{\mathrm{t}}\right)_{2}$ ] with excess potassium graphite in toluene results in elimination of potassium iodide and formation of $\left[\left\{\mathrm{U}\left(\mathrm{NN}^{\mathrm{fc}}\right)\right\}_{2}\left(\mu: \eta^{6}-\eta^{6}-\mathrm{C}_{6} \mathrm{H}_{5} \mathrm{Me}\right)\right](\mathbf{2 5})$ in $81 \%$ yield. The solid state structure of 25, Figure 9, reveals the by now familiar bridging arene motif with U-C bond distances ranging from 2.544(6) to 2.662(6) $\AA$ and a planar toluene ring. Complex 25 is best formulated as uranium(III) with a toluene dianion and acts as a four-electron reductant, as evidenced by its reaction with quinoxaline to generate the tetrameric complex $\left[\left\{\mathrm{U}\left(\mathrm{NN}^{\mathrm{fc}}\right)\left(\mu: \kappa^{1}-\kappa^{1}-\mathrm{C}_{8} \mathrm{H}_{6} \mathrm{~N}_{2}\right\}_{4}\right]\right.$ (26).

The year 2012 saw a significant expansion in the number of diuranium arene complexes in a comprehensive report detailing the synthesis, reactivity, and nature of a number of diuranium naphthalene, biphenyl, trans-stilbene, and para-terphenyl derivatives, Scheme 10 [44]. The key to this expansion was employing the uranium tris(ketimide) complex $\left[\mathrm{U}\left(\mathrm{NCBu}^{\mathrm{t}} \mathrm{Mes}\right)_{3}(\mathrm{I})(\mathrm{DME})\right]$, utilised in the synthesis of $\mathbf{9 a} / \mathbf{b}$, which enabled the incorporated arene to not have to be the reaction solvent and also 
for a number of charge states of the diuranium arene derivatives to be obtained. Treatment of $\left[\mathrm{U}\left(\mathrm{NCBu}^{\mathrm{t}} \mathrm{Mes}\right)_{3}(\mathrm{I})(\mathrm{DME})\right]$ with four equivalents of potassium graphite in DME solvent in the presence of half a molar equivalent of the relevant arene generated dipotassium salts of the dianionic complexes $\left[\left\{\mathrm{U}\left(\mathrm{NCBu}^{\mathrm{t}} \mathrm{Mes}\right)_{3}\right\}_{2}\left(\mu: \eta^{6}-\eta^{6}-\right.\right.$ arene $\left.)(\mathrm{K})_{2}\right]$ [arene $=$ naphthalene, 9a; arene $=$ biphenyl, 27a; arene $=$ trans-stilbene, 28a; arene $=$ para-terphenyl, 29a] in isolated yields of $46-67 \%$. The corresponding sodium salts $\mathbf{9 b}, \mathbf{2 7 b}-\mathbf{2 9 b}$, could also be prepared in similar yields though it was noted that these complexes are more lipophilic than the potassium salts which hampered their isolation. In all cases, where structural analysis was possible, the arene adopts a bridging coordination mode where the two uranium centres are bonded to opposite sides of the same ring and not in a slipped manner as is more common with these four arene derivatives. Like some examples above, the $\mathrm{C}-\mathrm{C}$ distances in the coordinated six-membered rings are elongated by $\sim 0.05 \AA$ compared to the free arenes. The occluded alkali metals interact principally with some mesityl rings and also some ketimide nitrogen centres, but other that a slight $(\sim 0.1 \AA)$ elongation of the respective U-N bond distances for the bridging ketimides the alkali metals seem to little affect the core diuranium arene fragment.

During these uranium ketimide studies it was determined that if only two equivalents of potassium graphite reductant was used, which would in principle present the correct stoichiometric ratio of alkali metal to uranium, then the monoanionic complexes $\left[\left\{\mathrm{U}\left(\mathrm{NCBu}^{\mathrm{t}} \mathrm{Mes}\right)_{3}\right\}_{2}\left(\mu: \eta^{6}-\eta^{6}\right.\right.$-arene $\left.)(\mathrm{K})\right]$ [arene $=$ benzene, 30; arene $=$ toluene, 31; arene $=$ naphthalene, 32; arene $=$ biphenyl, 33; arene $=$ trans-stilbene, 34; arene $=$ para-terphenyl, 35] were instead isolated in yields ranging from 43 to $83 \%$, Scheme 10. The solid state structures of 31.DME (Figure 10) and 31.KI were determined. Mixed-valence diuranium complexes are not common although the average U-C distances of $2.633 \AA$ is not discernably different from the examples above. A further point is that although the benzene and toluene complexes $\mathbf{3 0}$ and $\mathbf{3 1}$ are readily available for the monoanionic complexes in the dianionic form ( $\mathrm{cf} \mathbf{9 a} / \mathbf{b}$ ) these diuranium arene combinations were not available. It was proposed that arenes that are the most $\delta$-acidic, i.e. those that are more oxidising, are necessary to stabilise the higher 2- charge of the dianions than for the monoanions. 
Interestingly, it was discovered that the four dianionic complexes 9a, and 27a-29a could be oxidised with ferrocenium triflate or white phosphorus to afford the corresponding aforementioned monoanions 32-35, and these oxidations were reversible with reduction by potassium anthracenide with the notable observation that anthracene was not observed to be incorporated during reactions.

Reactivity studies of the diuranium arene ketimides were also reported, Scheme 10. The reactivity towards $\mathrm{C}_{8} \mathrm{H}_{8}$ will be discussed below in Section 6 below. Complex 9b reacts with two equivalents of $\mathrm{PhSSPh}$ in a four-electron reduction to give $\left[\left\{\mathrm{U}\left(\mathrm{NCBu}{ }^{\mathrm{t}} \mathrm{Mes}\right)_{3}\right\}_{2}(\mu-\mathrm{SPh})_{3}(\mathrm{Na})\right](\mathbf{3 6 b})$ in $60 \%$ isolated yield. In this reaction it is likely that $[\mathrm{Na}(\mathrm{SPh})]$ is eliminated but this was not established. More surprising though, is the observation that the monoanions react with 1.5 equivalents of $\mathrm{PhSSPh}$ in a three-electron reduction to afford, when 9a is used, 36a the potassium analogue of 36b. When PhNNPh is reacted with 31.DME or 31.KI the diuranium(V) imido complex $\left[\left\{\mathrm{U}\left(\mathrm{NCBu}{ }^{t} \mathrm{Mes}\right)_{3}\right\}_{2}(\mu-\mathrm{NPh})_{2}\right](37)$ is isolated in $63 \%$ yield in a five-electron reduction. It is proposed that $[\mathrm{K}(\mathrm{PhNNPh})]$ is the by-product of this reaction although its identity was not confirmed, but supporting evidence for this view comes from the fact that addition of two equivalents of $\mathrm{PhNNPh}$ affords a cleaner reaction than when only one equivalent is used. Complex 37 was also formed in reactions of $\mathrm{PhNNPh}$ with the other monoanionic complexes but it was noted that these reactions are not as clean.

Computational analyses of this series of ketimide complexes showed that there is an excellent energy match between the LUMOs of uncomplexed benzene and the frontier orbitals of uranium, whereas the benzene HOMO is mis-matched to uranium valence orbitals by $\sim 4 \mathrm{eV}$, and thus whereas $\pi$-bonding from benzene to uranium is negligible the principal interaction is $\delta$-bonding from uranium to arene as previously determined. In this regard an interesting isolobal relationship to the bonding in vanadium triple decker systems was identified drawing parallels between uranium and early d-metal chemistry.

Also in 2012, a new route for making complexes formulated as diuranium(III) arenedianion complexes was reported, Scheme 11 [45]. Storage of solutions of [U(L) 3 [L $=\mathrm{N}\left(\mathrm{SiMe}_{3}\right)_{2}$ or $\left.\mathrm{OC}_{6} \mathrm{H}_{3}-2,6-\mathrm{Bu}_{2}^{\mathrm{t}}\right]$ in benzene or toluene at $90{ }^{\circ} \mathrm{C}$ afforded the inverted 
sandwich complexes $\left[\left\{\mathrm{U}(\mathrm{L})_{2}\right\}_{2}\left(\mu: \eta^{6}-\eta^{6}\right.\right.$-arene $\left.)\right]$ [arene $=$ benzene, $\mathrm{L}=\mathrm{N}\left(\mathrm{SiMe}_{3}\right)_{2}$, 38a; arene $=$ toluene, $\mathrm{L}=\mathrm{N}\left(\mathrm{SiMe}_{3}\right)_{2}, \mathbf{3 8 b}$; arene = benzene, $\mathrm{L}=\mathrm{OC}_{6} \mathrm{H}_{3}-2,6-\mathrm{Bu}_{2}^{\mathrm{t}}, \mathbf{3 9} \mathbf{a}$; arene $=$ toluene, $\left.\mathrm{L}=\mathrm{OC}_{6} \mathrm{H}_{3}-2,6-\mathrm{Bu}_{2}^{\mathrm{t}}, 39 \mathbf{b}\right]$, in isolated yields varying from 14 to $45 \%$, to give complexes of generally similar structure to those of $10,11,13$, and 14 . For the amide, decomposition to the metallocycle $\left[\mathrm{U}\left\{\mathrm{N}\left(\mathrm{SiMe}_{3}\right)_{2}\right\}_{2}\left\{\mathrm{~N}\left(\mathrm{SiMe}_{3}\right)\left(\mathrm{SiMe}_{2} \mathrm{CH}_{2}\right)\right\}\right]$ was also observed which accounts, in part, for the lower yield of the amide derivatives. The reactions proceed via disproportionation, and for every equivalent of diuranium arene complex formed two equivalents of $\left[\mathrm{U}(\mathrm{L})_{3}\right]$ must be sacrificed as $\left[\mathrm{U}(\mathrm{L})_{4}\right]$ by-product. The benzene adducts form quicker than the toluene analogues inline with their respective $\delta$-acidities. Interestingly, despite only modest electronic and steric changes, the aryloxide ${ }^{-} \mathrm{OC}_{6} \mathrm{H}_{2}-2,4,6-\mathrm{Bu}_{3}^{\mathrm{t}}$ does not support this chemistry, although the diuranium arene derivative $\left[\left\{\mathrm{U}(\mathrm{L})_{2}\right\}_{2}\left(\mu: \eta^{6}-\eta^{6}\right.\right.$-arene $\left.)\right]$ [arene $=$ benzene, $\left.\mathrm{L}=\mathrm{OC}_{6} \mathrm{H}_{2}-2,4,6-\mathrm{Bu}_{3}^{\mathrm{t}}, \mathbf{4 0 a}\right]$ could be obtained by reaction of four equivalents of the free phenol with 38a. Also, $\left[\mathrm{U}(\mathrm{L})_{3}\right]$ reacts with molten biphenyl to afford $\left[\left\{\mathrm{U}(\mathrm{L})_{2}\right\}_{2}\left(\mu: \eta^{6}-\eta^{6}\right.\right.$-arene $\left.)\right]\left[\right.$ arene $=$ biphenyl, $\mathrm{L}=\mathrm{N}\left(\mathrm{SiMe}_{3}\right)_{2}, \mathbf{3 8 c}$; arene = biphenyl, $\mathrm{L}$ $\left.=\mathrm{OC}_{6} \mathrm{H}_{3}-2,6-\mathrm{Bu}_{2}^{\mathrm{t}}, 39 \mathrm{c}\right]$ in yields of 10 and $69 \%$, respectively.

Encouraged by these results, functionalised arenes were prepared utilising $\left[\mathrm{U}(\mathrm{L})_{3}\right][\mathrm{L}$ $=\mathrm{OC}_{6} \mathrm{H}_{3}-2,6-\mathrm{Bu}_{2}^{\mathrm{t}}$ only], Scheme 12. Treatment of four equivalents of $\left[\mathrm{U}(\mathrm{L})_{3}\right]$ with phenylsilane at $90{ }^{\circ} \mathrm{C}$ for 17 hours afforded $\left[\left\{\mathrm{U}(\mathrm{L})_{2}\right\}_{2}\left(\mu: \eta^{6}-\eta^{6}-\mathrm{C}_{6} \mathrm{H}_{5} \mathrm{SiH}_{3}\right)\right](\mathbf{4 1})$ but this complex could not be isolated from the $\left[\mathrm{U}(\mathrm{L})_{4}\right]$ by-product due to similar solubility properties. However, under the same conditions naphthalene and 9-bora-9bicyclononane $(\mathrm{HBBN})$ react with four equivalents of $\left[\mathrm{U}(\mathrm{L})_{3}\right]$ to afford $\left[\left\{\mathrm{U}(\mathrm{L})_{2}\right\}_{2}\left(\mu: \eta^{6}-\eta^{6}-\mathrm{C}_{10} \mathrm{H}_{7} \mathrm{BBN}\right)\right](\mathbf{4 2})$ and dihydrogen in low yield, Figure 11. After 6 days at $90{ }^{\circ} \mathrm{C}$ a mixture of $\mathbf{4 2}$ and benzene afforded free $\mathrm{C}_{10} \mathrm{H}_{7} \mathrm{BBN}$. This methodology could be extended to include borylation of benzene, toluene, and biphenyl to give $\left[\left\{\mathrm{U}(\mathrm{L})_{2}\right\}_{2}\left(\mu: \eta^{6}-\eta^{6}-\mathrm{C}_{6} \mathrm{H}_{4}-1-\mathrm{R}-4-\mathrm{BBN}\right)\right][\mathrm{R}=\mathrm{H}, \mathbf{4 3} \mathbf{a} ; \mathrm{R}=\mathrm{Me}, \mathbf{4 3} \mathbf{b} ; \mathrm{R}$ $=\mathrm{Ph}, \mathbf{4 3 c}]$ in isolated yields of 45,34 , and $11 \%$, respectively. Mechanistic studies on these reactions revealed them to be pseudo-second order with respect to $\left[\mathrm{U}(\mathrm{L})_{3}\right]$. A computational study of the reaction mechanisms was also conducted. For arene complex formation, the arene binds to a uranium centre in a concerted step with transfer of one $\mathrm{L}$ group from the arene-bound uranium to another $\left[\mathrm{U}(\mathrm{L})_{3}\right]$ molecule to produce $\left[\mathrm{U}(\mathrm{L})_{2}\left(\eta^{6}\right.\right.$-arene $\left.)\right]$; a second concerted step then occurs involving binding of a uranium to the other side of the arene along with another $\left[\mathrm{U}(\mathrm{L})_{3}\right]$ group accepting a $\mathrm{L}$ 
group from the newly bound uranium centre. For the borylation reactions, these reactions were calculated to be thermodynamically favourable, not because of the elimination of dihydrogen, but because the borylated arene produces a more stable diuranium arene unit. The mechanism involves a concerted electrophilic aromatic substitution where the HBBN adds to a carbon atom of the arene then $\mathrm{H}_{2}$ is eliminated. An adduct whereby the HBBN has added to a carbon atom of the arene and the B-H is coordinated to uranium was identified in the reaction scheme at lower energy than the concerted reaction, however this route then encounters a major barrier to elimination of $\mathrm{H}_{2}$ since the $\mathrm{B}-\mathrm{H}$ and arene $\mathrm{C}-\mathrm{H}$ bonds are disposed on opposite sides of the arene so that route can be discounted.

In 2013 further investigations into the electronic structure of the diuranium arene complexes 6a were reported [46]. As described for studies of 10, ${ }^{1} \mathrm{H}$ NMR studies of 6a show that the bridging toluene in 6a exchanges slowly with deuterated benzene (5\% exchange after 24 hours) and does not exchange with para-xylene. Again, this is entirely in line with the $\delta$-acidities of the respective arenes. ${ }^{1} \mathrm{H}$ NMR studies also suggest that the diuranium arene complex $\mathbf{6 a}$ is retained in solution with no evidence for monomer units being observed. Interestingly, reasonably intense $\left(\varepsilon \sim 200-600 \mathrm{M}^{-1}\right.$ $\mathrm{cm}^{-1}$ ) absorptions are observed in the NIR region of the electronic absorption spectrum of $\mathbf{6 a}\left(7,000-9,000 \mathrm{~cm}^{-1}\right)$ which was ascribed to evidence of intensity stealing and significant covalency in the $\delta$-bonding. These transitions are much less intense than observed in 24, although 24 exhibits unusually large and unique absorptions compared to all other diuranium arene complexes. Variable temperature magnetisation studies revealed a maximum in the $\chi$ vs T plot for $6 \mathbf{a}$ at $110 \mathrm{~K}$ which is indicative of antiferromagnetic communication between the two uranium centres, which again contrasts to $\mathbf{2 4}$. A DFT study of $\mathbf{6 a}$ reveals energetically closely spaced spin states and so CASSCF calculations were performed. Interestingly, the CASSCF calculations show the ground state to be the singlet state, but the triplet and quintet states are only 2.9 and $10.5 \mathrm{~kJ} \mathrm{~mol}^{-1}$ higher in energy. Irrespective of the spin state, the basic bonding picture of two sets of $\delta$-bonds emerges, and these calculations reveal that the 'high-spin' quintet state consists of one dominating configuration which contributes $87 \%$ to the total wavefunction. The singlet and triplet states are multi-reference and contribute several configurations to the total wavefunction. The 
septet state was calculated to be some $144 \mathrm{~kJ} \mathrm{~mol}^{-1}$ higher in energy than the singlet. The atomic charges extracted from the CASSCF calculations are 2.33 for uranium; this is consistent with a uranium(III) formulation which is now the consensus view of these arene complexes. This is further reinforced by a XANES study of 6a and a series of reference complexes which places the uranium centres in $\mathbf{6 a}$ in the region that correlates to uranium(III).

Complex 24, like several other diuranium arene complexes, is prepared in relatively low yield (20\%). In an attempt to prepare a diuranium arene complex with a similar steric and electronic environment the synthesis of a $\beta$-diketiminate-supported complex was recently reported [47]. Treatment of the complex $\left[\mathrm{U}(\mathrm{L})(\mathrm{I})_{2}(\mathrm{THF})_{2}\right][44, \mathrm{~L}=$ $\mathrm{HC}(\mathrm{CMeNDipp})_{2}$; Dipp = 2,6-diisopropylphenyl] with potassium graphite in benzene afforded $\left[\{\mathrm{U}(\mathrm{L})(\mathrm{I})\}_{2}\left(\mu: \eta^{6}-\eta^{6}-\mathrm{C}_{6} \mathrm{H}_{6}\right)\right]$, Scheme 13 and Figure 12; however, this complex was prepared in only $\sim 3 \%$ yield. Cleavage reactions of $\beta$-diketiminate ligands coordinated to uranium have been reported before [48] and so it seems that this ligand is not well-suited to the reducing conditions necessary to prepare inverted sandwich complexes.

\subsection{Diuranium(V) Arenes}

For the first 11 years of diuranium arene chemistry all reported complexes conformed to the description of uranium(III) centres bridged by arene dianions. However, in 2011 a new class of diuranium arene complex emerged, Scheme $14[18,19]$. Reduction of the uranium triamide chloride complexes [U(Ts $\left.\left.{ }^{\mathrm{Ar}}\right)(\mathrm{Cl})(\mathrm{THF})\right](\mathrm{Ar}=3,5-$ xylyl or para-tolyl) with potassium graphite afforded complexes $\mathbf{1}$ and $\mathbf{3}$ in 65 and 95\% isolated yields, respectively. What is immediately salient about $\mathbf{1}$ and $\mathbf{3}$ are the presence of three amide groups per uranium, by virtue of their incorporation to a tripodal ligand, compared to the usual arrangement of two anionic co-ligands in addition to the arene bridge, as is the case for the majority of complexes described above. In this regard complexes $\mathbf{1}$ and $\mathbf{3}$ are reminiscent of the trisketimides $\mathbf{9 a} / \mathbf{b}$ and 27-35, but importantly $\mathbf{1}$ and $\mathbf{3}$ are neutral with no alkali metal ions available for inclusion like $\mathbf{9 a} / \mathbf{b}$ and $\mathbf{2 7 - 3 5}$. Three formulations for $\mathbf{1}$ and $\mathbf{3}$ can be advanced: a neutral arene and uranium(III) centres; an arene dianion and uranium(IV) ions; or an arene tetraanion and uranium(V) centres. Surprisingly, the characterisation data support the latter formulation, but the $\delta$-bonding in these complexes renders this 
assignment a formalism. Specifically, the magnetic data do not tend to zero as would be expected for uranium(IV) and uranium(III) centres could be ruled out on the basis of the magnetisation data and the electronic absorption spectrum. The magnetic data are consistent with uranium(V) centres and absorptions at 6815 and $6740 \mathrm{~cm}^{-1}(\varepsilon=82$ and $120 \mathrm{M}^{-1} \mathrm{~cm}^{-1}$ ) for $\mathbf{1}$ and $\mathbf{3}$, respectively, are a signature, though not absolute proof, of uranium(V). Interestingly the $\mathrm{U}-\mathrm{C}$ bond distances for $\mathbf{1}$, Figure 13, are relatively long [2.651(4)-2.698(4) $\AA$ ] and the U-N bonds are relatively short; the data and structure of $\mathbf{3}$ are very similar to $\mathbf{1}$. DFT studies on $\mathbf{1}$ and $\mathbf{3}$ reveal one unpaired felectron per uranium centre and relatively high atomic charges at uranium of ca +3.0 and charges of ca -4.4 on the arenes. In support of these data low temperature EPR data could be collected for complex 3, whose other characterisation data are very similar to 1. Under the measurement conditions a response is not expected from the non-Kramers ion uranium(IV), whereas the EPR spectrum is not anisotropic enough for uranium(III) which is already discounted from the other data. The absorption in the EPR spectrum is only observable below $30 \mathrm{~K}$ which is indicative of unpaired $\mathrm{f}$ electrons. The EPR absorption is clearly not due to a ligand-based or free-electron and thus is assignable as a f-electron of uranium(V). Although the pairing of formal and oxidising uranium(V) centres with an arene tetraanion may seem an unlikely combination, the $\delta$-bonding will stabilise this interaction and as a tetraanion the toluene bridges in $\mathbf{1}$ and $\mathbf{3}$ are 10 $\pi$-electron systems that satisfy Huckel's $4 n+2 \pi$ electron rule. Therefore, a not insignificant energetic penalty would be expected to have to be paid to break the tetraanion formulation and hence it is stable. However, these molecules are clearly very reactive and once the arene starts to reduce substrates the $10 \pi$ stabilising effect is lost. In addition to reducing substrates the oxidising uranium(V) centres are indeed often reduced to give uranium(IV) products, unless the substrate can accept all of the four-electrons available for reductions in which case the uranium centres can retain their pentavalent states. Complexes $\mathbf{1}$ and $\mathbf{3}$ have demonstrated utility in the preparation of the cyclobutadienyl and diphosphacyclobutadienyl complexes $\mathbf{2}$ and $\mathbf{4}$, respectively, and the first example of a uranium-cobalt bond which could not be prepared by salt-, amine-, or alkaneelimination strategies [18]. Additionally, 1 was shown to react with white phosphorus to afford the Zintl cluster $\left[\left\{\mathrm{U}\left(\mathrm{Ts}^{\mathrm{Tol}}\right)\right\}_{3}\left(\mu_{3}-\eta^{2}: \eta^{2}: \eta^{2}-\mathrm{P}_{7}\right)\right]$ [49] in a multi-electron reaction that promotes catenation of phosphorus. 
A year later in 2012 the synthesis of another complex assignable as diuranium(V) arene tetraanion was reported. Specifically, reaction of the uranium siloxide complex $\left[\left\{\mathrm{U}\left(\mathrm{OSi}\left[\mathrm{OBu}^{\mathrm{t}}\right]_{3}\right)_{3}\right\}_{2}\right]$ with toluene afforded $\left[\left\{\mathrm{U}\left(\mathrm{OSi}\left[\mathrm{OBu}^{\mathrm{t}}\right]_{3}\right)_{3}\right\}_{2}\left(\mu: \eta^{6}-\eta^{6}-\mathrm{C}_{6} \mathrm{H}_{5} \mathrm{Me}\right)\right]$ (45) in 89\% yield, Scheme 15 [50]. Notably, the U-C distances [mean 2.692(3) Å], Figure 14, are towards the high end of uranium arene U-C distances like $\mathbf{1}$ and $\mathbf{3}$. The uranium oxidation states were not assigned in the preliminary report, but a year later in 2013 a fuller study concluded that the uranium centres in $\mathbf{4 5}$ are best described as pentavalent with tetraanionic arenes just like in 1 and 3 [51]. Importantly, complex 45 could be sequentially reduced to the monoanionic $\left[\left\{\mathrm{U}\left(\mathrm{OSi}\left[\mathrm{OBu}^{\mathrm{t}}\right]_{3}\right)_{3}\right\}_{2}\left(\mu: \eta^{6}-\eta^{6}-\right.\right.$ $\left.\left.\mathrm{C}_{6} \mathrm{H}_{5} \mathrm{Me}\right)(\mathrm{K})\right]$ (46) and dianionic $\left[\left\{\mathrm{U}\left(\mathrm{OSi}\left[\mathrm{OBu}^{\mathrm{t}}\right]_{3}\right)_{3}\right\}_{2}\left(\mu: \eta^{6}-\eta^{6}-\mathrm{C}_{6} \mathrm{H}_{5} \mathrm{Me}\right)(\mathrm{K})_{2}\right]$ (47) forms which are diuranium(IV/V) arene tetraanion and diuranium(IV/IV) arene tetraanion formulations, respectively, Scheme 15. Interestingly, the change in uranium oxidation state can be monitored by the change in uranium-arene U-C bond lengths. For neutral diuranium(V) 45 the U-C distances span the range 2.689(3) to 2.695(3) $\AA$, this decreases to 2.602(9) to 2.674(13) $\AA$ for monoanionic diuranium(IV/V) 46, and finally reaches 2.589(4) to 2.621(3) $\AA$ for dianionic (IV/IV) 47. DFT calculations revealed that when the f-occupancy was set to $\mathrm{f}^{2}$ for uranium(IV) in neutral 45 it dissociated in silico and for the uranium(III) formulation the bond lengths were too long. However, when the f-occupancy was set to $\mathrm{f}^{1}$ the computational structure converged to a geometry with bond distances that closely matched the experimental structure. Allowing the f-occupancy to vary resulted in an electronic description that closely matches those of $\mathbf{1}$ and $\mathbf{3}$, namely essentially one unpaired electron per uranium and a tetraanionic arene. When calculations were conducted on 46 and 47 what emerges is that as electrons are injected into the molecules they occupy nonbonding f-orbitals since the arene at $10 \pi$-electrons is already electronically saturated and the remaining $\psi_{6}$ orbital is too high-lying to accept electrons. Lastly, magnetic studies and CASSCF calculations confirm the overall bonding picture and verify the diuranium $(V)$ arene tetraanion formulation.

\section{Cycloheptatrienyl Complexes of Uranium}

Although there are a relatively large number of transition metal cycloheptatrienyl complexes reported in the literature [52], it is interesting to note that uranium analogues are exceptionally rare. Aside from the sandwich complex $\left[\mathrm{U}\left(\eta^{7}-\right.\right.$ 
$\left.\left.\mathrm{C}_{7} \mathrm{H}_{7}\right)_{2}\right]\left[\mathrm{K}\left(\mathrm{C}_{12} \mathrm{H}_{24} \mathrm{O}_{6}\right)\right]$ [53], the only other example of a uranium cycloheptatrienyl complex is that of the inverse sandwich separated ion pair complex $\left[\left(\mathrm{H}_{4} \mathrm{~B}\right)_{3} \mathrm{U}\left(\mu: \eta^{7}-\eta^{7}-\right.\right.$ $\left.\left.\mathrm{C}_{7} \mathrm{H}_{7}\right) \mathrm{U}\left(\mathrm{BH}_{4}\right)_{3}\right]\left[\mathrm{U}\left(\mathrm{BH}_{4}\right)_{2}(\mathrm{THF})_{5}\right]$ (48), Scheme 16, reported in 1994 [54]. Complex 48 was prepared by treatment of the borohydride complex $\left[\mathrm{U}\left(\mathrm{BH}_{4}\right)_{4}\right]$ with $\left[\mathrm{K}\left(\mathrm{C}_{7} \mathrm{H}_{9}\right)\right]$ in the presence of 1,2-bis(dimethylphosphino)ethane (dmpe). Although the expected product was $\left[\left(\mathrm{H}_{4} \mathrm{~B}\right)_{3} \mathrm{U}\left(\mu: \eta^{7}-\eta^{7}-\mathrm{C}_{7} \mathrm{H}_{7}\right) \mathrm{U}\left(\mathrm{BH}_{4}\right)_{3}\right][\mathrm{K}]$, complex 48 was instead isolated during recrystallisation. Although no theoretical studies of $\mathbf{4 8}$ have been reported it seems likely that $\delta$-bonding will dominate the bonding of the inverse sandwich unit, as has been suggested for the bonding scheme of $\left[\mathrm{U}\left(\mu: \eta^{7}-\eta^{7}-\mathrm{C}_{7} \mathrm{H}_{7}\right)_{2}\right]^{-}[55]$, which would also be consistent with the planar $\mathrm{C}_{7} \mathrm{H}_{7}$ ring revealed by an $\mathrm{X}$-ray diffraction study, Figure 15. When the synthesis was conducted with $\left.\left[\left\{\mathrm{U}_{(\mathrm{NEt}}\right)_{4}\right\}_{2}\right]$ in the absence of dmpe the complex $\left[\left(\mathrm{Et}_{2} \mathrm{~N}\right)_{3} \mathrm{U}\left(\mu: \eta^{7}-\eta^{7}-\mathrm{C}_{7} \mathrm{H}_{7}\right) \mathrm{U}\left(\mathrm{NEt}_{2}\right)_{3}\right][\mathrm{K}](49)$ was isolated and further derivatised as its 18-crown-6 ether adduct. Although the crystal structure of 49 could not be determined, its characterisation data, and those of $\mathbf{4 8}$, are consistent with the proposed formulation and the assignment of an oxidation state of uranium(IV) which suggests the cycloheptatrienyl ligand bears a -3 charge in both complexes.

\section{Cyclooctatetraenyl Complexes of Uranium}

As exemplified by uranocene [13], the cyclooctatetraenyl ligand is usually found in sandwich complexes where it is bonded to one metal only. However, like the aforementioned arene ligands cyclooctatetraenyl can also bridge two uranium centres in inverse sandwich complexes, although like cycloheptatrienyl analogues this bonding mode is very rare. The first example of a bridging cyclooctatetraenyl ligand was reported in 2000, the same year as the first inverted arene sandwich complexes $\mathbf{6 a} / \mathbf{b}$ [36]. In a three-electron reduction reaction, it was reported that two equivalents of $\left[U\left(\eta^{5}-C_{5} M_{5}\right)_{3}\right]$ reacted with three equivalents of $\mathrm{C}_{8} \mathrm{H}_{8}$ to afford $\left[\left\{U\left(\eta^{5}-\mathrm{C}_{5} \mathrm{Me}_{5}\right)\left(\eta^{8}-\right.\right.\right.$ $\left.\left.\left.\mathrm{C}_{8} \mathrm{H}_{8}\right)\right\}_{2}\left(\mu: \eta^{3}-\eta^{3}-\mathrm{C}_{8} \mathrm{H}_{8}\right)\right] \quad(\mathbf{5 0})$ in $85 \%$ isolated yield, Scheme 17 [56]. The cyclooctatetraenyl ligand does not bridge symmetrically, which was rationalised on the basis of the sterically demanding nature of the $\left[\mathrm{U}\left(\eta^{5}-\mathrm{C}_{5} \mathrm{Me}_{5}\right)\left(\eta^{8}-\mathrm{C}_{8} \mathrm{H}_{8}\right)\right]^{+}$fragment, and instead binds like two allyl fragments to each uranium ion, Figure 16. The formation and stability of $\mathbf{5 0}$ is notable because $\mathbf{5 0}$ contains the components of the very stable uranocene but uranocene is not extruded from 50. Indeed, 50 only decomposes at elevated temperatures and it does not decompose to uranocene. 
Examination of the reaction stoichiometry reveals that during the formation of $\mathbf{5 0}$ uranium is oxidised from (III) to (IV) and coupled $\left(\mathrm{C}_{5} \mathrm{Me}_{5}\right)_{2}$ is formed so overall a three-electron reduction is effected. Later in 2004 it was shown that the diuranium arene complex 10 reacts with three equivalents of $\mathrm{C}_{8} \mathrm{H}_{8}$ to afford $\mathbf{5 0}$ [38], thus demonstrating more multi-electron redox chemistry of $\mathbf{1 0 .}$

In the same 2002 publication in which the synthesis of $\mathbf{9 a} / \mathbf{b}$ were reported, the synthesis of a diuranium inverted sandwich complex of the cyclooctatetraenyl ligand was disclosed [37]. Addition of two equivalents of $\mathrm{C}_{8} \mathrm{H}_{8}$ to dimeric 9a/b afforded a mixture of $\left[\mathrm{U}\left(\mathrm{NCBu}{ }^{\mathrm{t}} \mathrm{Mes}\right)_{3}\left(\eta^{8}-\mathrm{C}_{8} \mathrm{H}_{8}\right)(\mathrm{M})\right](\mathbf{5 1 a} / \mathbf{b})$ and $\left[\left\{\mathrm{U}\left(\mathrm{NCBu}{ }^{t} \mathrm{Mes}\right)_{3}\right\}_{2}\left(\mu: \eta^{8}-\eta^{8}-\right.\right.$ $\left.\mathrm{C}_{8} \mathrm{H}_{8}\right)$ ] (52). These two complexes could be separated due to their different solubilities and the former could be converted to the latter by treatment with $\left[\mathrm{U}\left(\mathrm{NCBu}^{\mathrm{t}} \mathrm{Mes}\right)_{3}(\mathrm{I})(\mathrm{DME})\right]$. As would be expected considering the greater size of the planar $\mathrm{C}_{8}$ ring compared to the planar $\mathrm{C}_{6}$ ring, the mean $\mathrm{U}-\mathrm{C}$ distance in $\mathbf{5 2}(2.822 \AA)$, Figure 17, is longer than the mean U-C bond length in 9a (2.634 $\AA$ ). Potentially weaker $\delta$-bonding in $\mathbf{5 2}$ compared to $\mathbf{9 a}$ was also apparent from theoretical calculations which presumably reflects the large size of cyclooctatetraenyl as described in Section 1.6..

\section{Summary and Outlook}

Although the organometallic chemistry of arene uranium sandwich complexes has been burgeoning for over half a century, the advent of inverted sandwich complexes is a relatively recent development. Nevertheless, over the past 20 years major advances have occurred, and of the $C_{n}(n=4-8)$ series only $C_{5}$ has eluded isolation in a complex. Whilst it is clear that $\mathrm{C}_{4}, \mathrm{C}_{7}$, and $\mathrm{C}_{8}$ inverted sandwich complexes remain rare, the $\mathrm{C}_{6}$ class is burgeoning with over 40 complexes now reported. Although the likely bonding of a bridging $\mathrm{C}_{5}$ to uranium is unknown it would be anticipated to be dominated by $\pi$-interactions as is the case for $\mathrm{C}_{4}$ complexes. However, after this point, $\delta$-bonding appears to dominate the bonding of $\mathrm{C}_{6-8}$ uranium interactions. Although uranium(III) arene dianions are the dominant formulation of $\mathrm{C}_{6}$ derivatives, it is clear that a small number of diuranium(V) arene tetraanions are stable. This can be accounted for on the basis of Huckel's $4 n+2 \pi$-electron rule and stabilisation by the $\delta$ bonding. Furthermore, this looks even more credible given the recent report of an arene tetraanion coordinated to yttrium where the assignment of metal oxidation state 
is more clear-cut [57]. These arene bridges, especially the $\mathrm{C}_{6}$ systems, clearly involve covalent $\delta$-bonding, and this generates and supports some unusual effects and phenomena such as antiferromagnetic exchange with a Néel temperature of $110 \mathrm{~K}$, single molecule magnetism, and unusual examples of mixed valence diuranium complexes. Where reactivity is concerned, these complexes can effect multi-electron redox chemistry, novel arene functionalisation reactions, cycloadditions, and metalmetal bond formation that have no equivalent in d-block chemistry. The relatively rapid growth of the area and the fascinating reactions and magnetic phenomena that have already been observed augers well for the future of this area.

\section{Acknowledgements}

The Author is grateful for the continued and generous support of the Royal Society, ERC, EPSRC, University of Nottingham, and the UK National Nuclear Laboratory.

\section{References}

1. L. T. Reynolds, G. Wilkinson, J. Inorg. Nucl. Chem. 2 (1956) 246-253.

2. C. -H. Wong, T. -M. Yen, T. -Y. Lee, Acta Cryst. 18 (1965) 340-345.

3. M. Ephritikhine, Dalton Trans. (2006) 2501-2516.

4. A. R. Fox, S. C. Bart, K. Meyer, C. C. Cummins, Nature 455 (2008) 341-349.

5. M. B. Jones, A. J. Gaunt, Chem. Rev. 113 (2013) 1137-1198 and references therein.

6. R. J. Baker, Coord. Chem. Rev. 23-24 (2012) 2843-2871.

7. T. W. Hayton, Dalton Trans. 39 (2010) 1145-1158.

8. T. W. Hayton, Chem Commun. 49 (2013) 2956-2973.

9. B. M. Gardner, S. T. Liddle, Eur. J. Inorg. Chem. (2013) 3753-3770.

10. H. S. La Pierre, K. Meyer, Inorg. Chem. 52 (2013) 529-539.

11. D. M. King, S. T. Liddle, Coord. Chem. Rev. 266-267 (2014) 2-15.

12. H. S. La Pierre, K. Meyer, Prog. Inorg. Chem. in press.

13. A. Streitwieser, U. Müller-Westerhoff, J. Am. Chem. Soc. 90 (1968) 7364-7364.

14. A. Zalkin, K. N. Raymond, J. Am. Chem. Soc. 91 (1969) 5667-5668.

15. D. Seyferth, Organometallics 23 (2004) 3562-3583.

16. D. Seyferth, Organometallics 22 (2003) 2-20.

17. D. Patel, J. McMaster, W. Lewis, A. J. Blake, S. T. Liddle, Nat. Commun. 4 (2013) 2323, doi:10.1038/ncomms3323. 
18. D. Patel, F. Moro, J. McMaster, W. Lewis, A. J. Blake, S. T. Liddle, Angew. Chem. Int. Ed. 50 (2011) 10388-10392.

19. D. Patel, F. Tuna, E. J. L. McInnes, J. McMaster, W. Lewis, A. J. Blake, S. T. Liddle, Dalton Trans. 42 (2013) 5224-5227.

20. D. Baudry, M. Ephritikhine, F. Nief, L. Ricard, F. Mathey, Angew. Chem. Int. Ed. 29 (1990) 1485-1486.

21. M. Ephritikhine, Organometallics 32 (2013) 2464-2488.

22. H. A. Zinnen, J. J. Pluth, W. J. Evans, Chem. Commun. (1980) 810-812.

23. D. M. Barnhart, R. J. Butcher, D. L. Clark, J. C. Gordon, J. G. Watkin, B. D. Zwick, New J. Chem. 19 (1995) 495-503.

24. M. Cesari, U. Pedretti, A. Zazetta, G. Lugli, W. Marconi, Inorg. Chim. Acta 5 (1971), 439-444.

25. F. A. Cotton, W. Schwotzer, Organometallics 4 (1985) 942-943.

26. F. A. Cotton, W. Schwotzer, C. Q. Simpson II, Angew. Chem. Int. Ed. 25 (1986) 637-639.

27. G. C. Campbell, F. A. Cotton, J. F. Haw, W. Schwotzer, Organometallics 5 (1986) 274-279.

28. W. G. Van Der Sluys, C. J. Burns, J. C. Huffman, A. P. Sattelberger, J. Am. Chem. Soc. 110 (1988) 5924-5925.

29. F. A. Cotton, W. Schwotzer, Organometallics 6 (1987) 1275-1280.

30. D. Baudry, E. Bulot, P. Charpin, M. Ephritikhine, M. Lance, M. Nierlich, J. Vigner, J. Organomet. Chem. 371 (1989) 155-162.

31. W. J. Evans, S. A. Kozimor, W. R. Hillman, J. W. Ziller, Organometallics 24 (2005) 4676-4683.

32. S. C. Bart, F. W. Heinemann, C. Anthon, C. Hauser, K. Meyer, Inorg. Chem. 48 (2009) 9419-9426.

33. O. P. Lam, S. C. Bart, H. Kameo, F. W. Heinemann, K. Meyer, Chem. Commun. 46 (2010) 3137-3139.

34. H. S. La Pierre, H. Kameo, D. P. Halter, F. W. Heinemann, K. Meyer, Angew. Chem. Int. Ed. 53 (2014) 7154-7157.

35. H. S. La Pierre, A. Scheurer, F. W. Heinemann, W. Hieringer, K. Meyer, Angew. Chem. Int. Ed. 53 (2014) 7158-7162.

36. P. L. Diaconescu, P. L. Arnold, T. A. Baker, D. J. Mindiola, C. C. Cummins, J. Am. Chem. Soc. 122 (2000) 6108-6109. 
37. P. L. Diaconescu, C. C. Cummins, J. Am. Chem. Soc. 124 (2002) 7660-7661.

38. W. J. Evans, S. A. Kozimor, J. W. Ziller, N. Kaltosyannis, J. Am. Chem. Soc. 126 (2004) 14533-14547.

39. W. J. Evans, C. A. Traina, J. W. Ziller, J. Am. Chem. Soc. 131 (2009) 1747317481.

40. D. P. Mills, F. Moro, J. McMaster, J. van Slageren, W. Lewis, A. J. Blake, S. T. Liddle, Nat. Chem. 3 (2011) 454-460.

41. D. P. Mills, F. Moro, J. van Slageren, S. T. Liddle, unpublished results.

42. D. E. Morris, R. E. Da Re, K. C. Jantunen, I. Castro-Rodriquez, J. L. Kiplinger, Organometallics 23 (2004) 5142-5153.

43. M. J. Monreal, S. I. Khan, J. L. Kiplinger, P. L. Diaconescu, Chem. Commun. 47 (2011) 9119-9121.

44. P. L. Diaconescu, C. C. Cummins, Inorg. Chem. 51 (2012) 2902-2916.

45. P. L. Arnold, S. M. Mansell, L. Maron, D. McKay, Nat. Chem. 4 (2012) 668674.

46. B. Vlaisavljevich, P. L. Diaconescu, W. L. Lukens Jnr, L. Gagliardi, C. C. Cummins, Organometallics 32 (2013) 1341-1352.

47. A. J. Wooles, W. Lewis, A. J. Blake, S. T. Liddle, Organometallics 32 (2013) 5058-5070.

48. P. B. Hitchcock, M. F. Lappert, D. -S. Liu, J. Organomet. Chem. 488 (1995) 241-248.

49. D. Patel, F. Tuna, E. J. L. McInnes, W. Lewis, A. J. Blake, S. T. Liddle, Angew. Chem. Int. Ed. 52 (2013) 13334-13337.

50. V. Mougel, C. Camp, J. Pécaut, C. Copéret, L. Maron, C. E. Kefalidis, M. Mazzanti, Angew. Chem. Int. Ed. 51 (2012) 12280-12284.

51. C. Camp, V. Mougel, J. Pécaut, L. Maron, M. Mazzanti, Chem. Eur. J. 19 (2013) 17528-17540.

52. M. L. H. Green, D. K. P. Ng, Chem. Rev. 95 (1995) 439-473.

53. T. Arliguie, M. Lance, M. Nierlich, J. Vigner, M. Ephritikhine, J. Chem. Soc. Chem. Commun. (1995) 183-184.

54. T. Arliguie, M. Lance, M. Nierlich, J. Vigner, M. Ephritikhine, J. Chem. Soc. Chem. Commun. (1994) 847-848.

55. J. Li, B. E. Bursten, J. Am. Chem. Soc. 119 (1997) 9021-9032. 
56. W. J. Evans, G. W. Nyce, J. W. Ziller, Angew. Chem. Int. Ed. 39 (2000) 240242.

57. W. Huang, F. Dulong, T. Wu, S. I. Khan, J. T. Miller, T. Cantat, P. L. Diaconescu, Nat. Commun. 4 (2013) 1448, doi:10.1038/ncomms2473.

\section{Figures and Schemes}

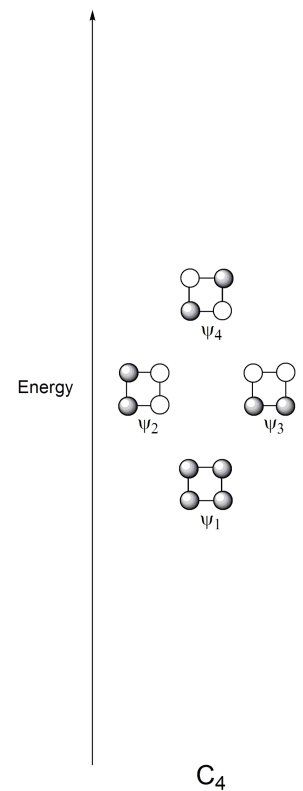

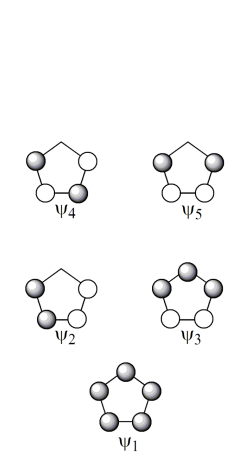

$\mathrm{C}_{5}$
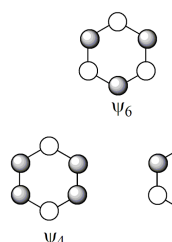<smiles>C1COCCO1</smiles>

o

$\psi_{1}$

$\mathrm{C}_{6}$

$\psi_{5}$

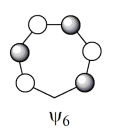<smiles>O1OOOOO1</smiles><smiles>C1OOCOOO1</smiles><smiles>C1COOOO1</smiles><smiles>C1COOOOO1</smiles><smiles>C1OOOOO1</smiles>

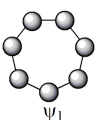

$\mathrm{C}_{7}$<smiles>C1COOOOOO1</smiles><smiles>o1oooooooooo1</smiles><smiles>O1OOOOOOOOOOO1</smiles><smiles>o1oooooooooo1</smiles><smiles>o1oooooo1</smiles>

Figure 1. Frontier $\pi$ molecular orbital combinations for aromatic arene ligands $C_{4}-C_{8}$. The energies of the $\psi$ orbitals are not absolute. 


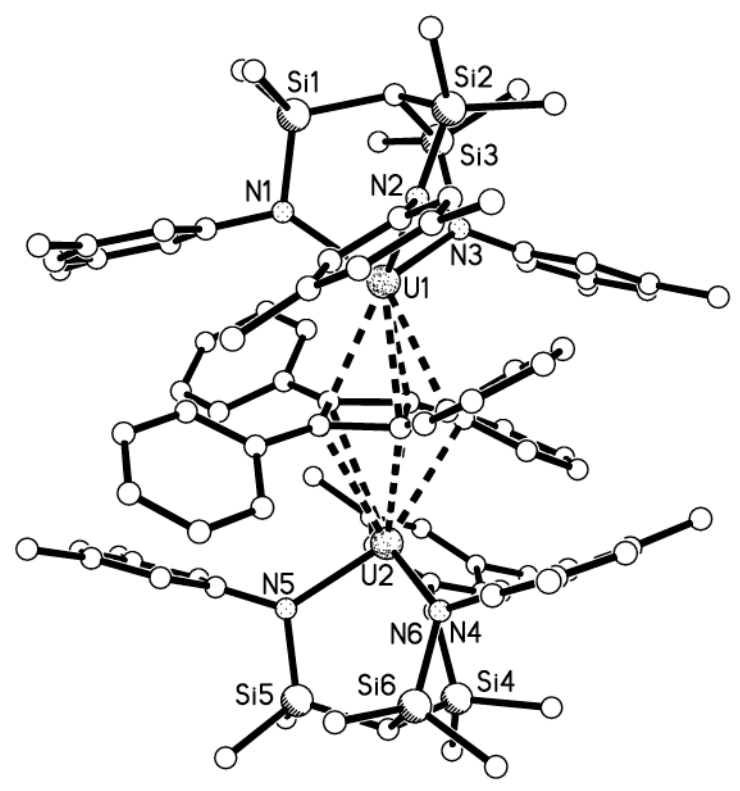

Figure 2. Molecular structure of $\mathbf{2}$ with selective labelling and hydrogen atoms omitted for clarity [17].

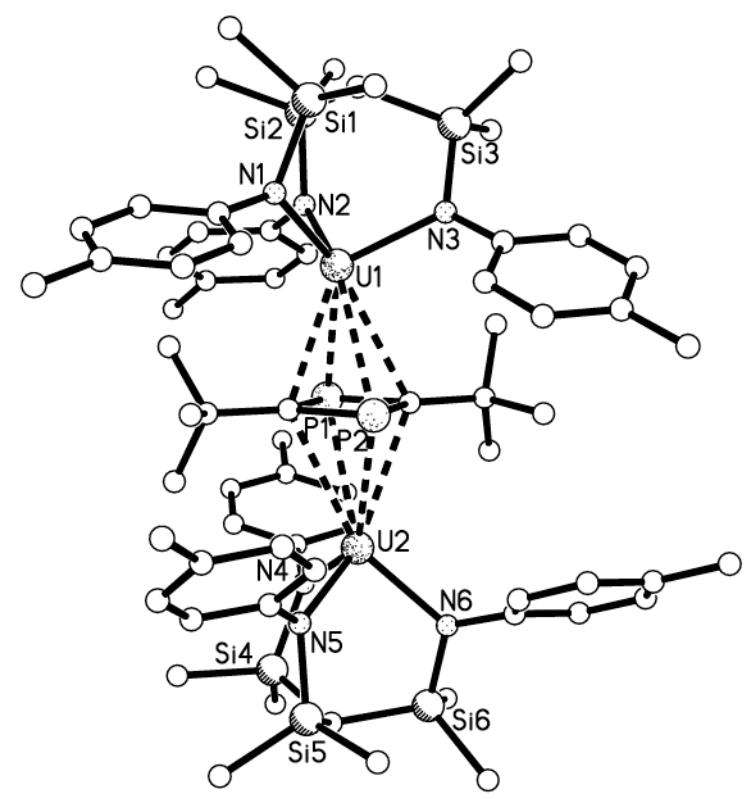

Figure 3. Molecular structure of $\mathbf{4}$ with selective labelling and hydrogen atoms omitted for clarity [17]. 


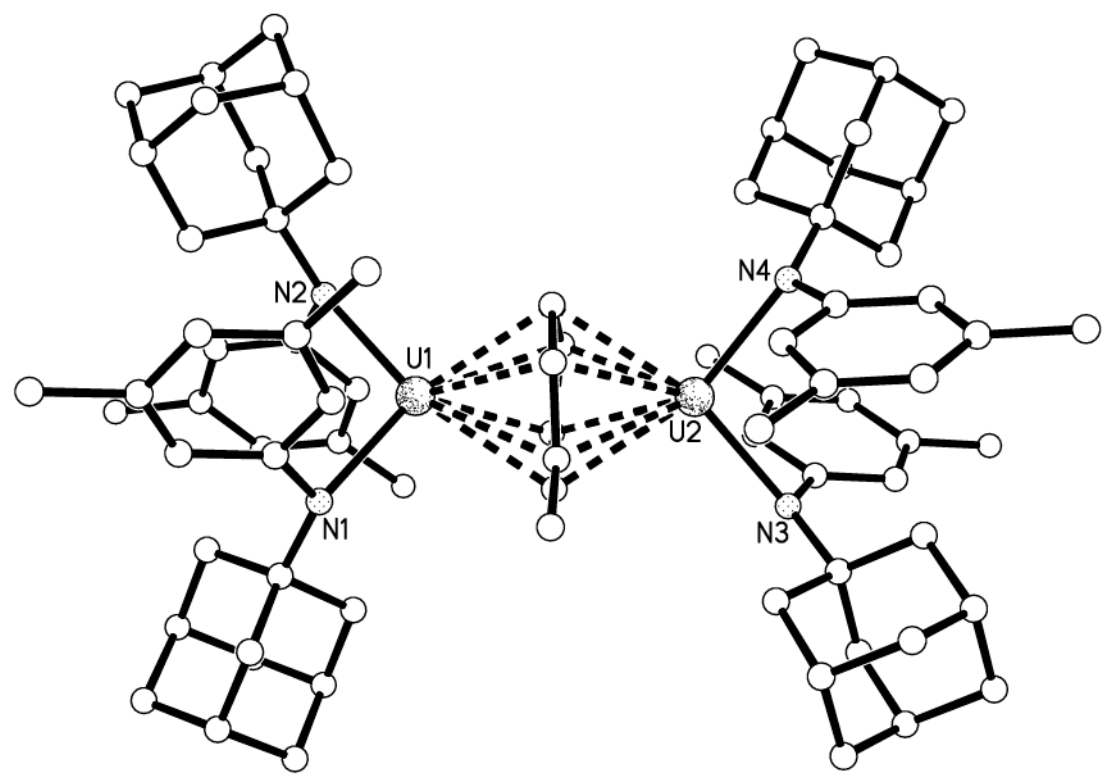

Figure 4. Molecular structure of $\mathbf{6 b}$ with selective labelling and hydrogen atoms omitted for clarity [36].

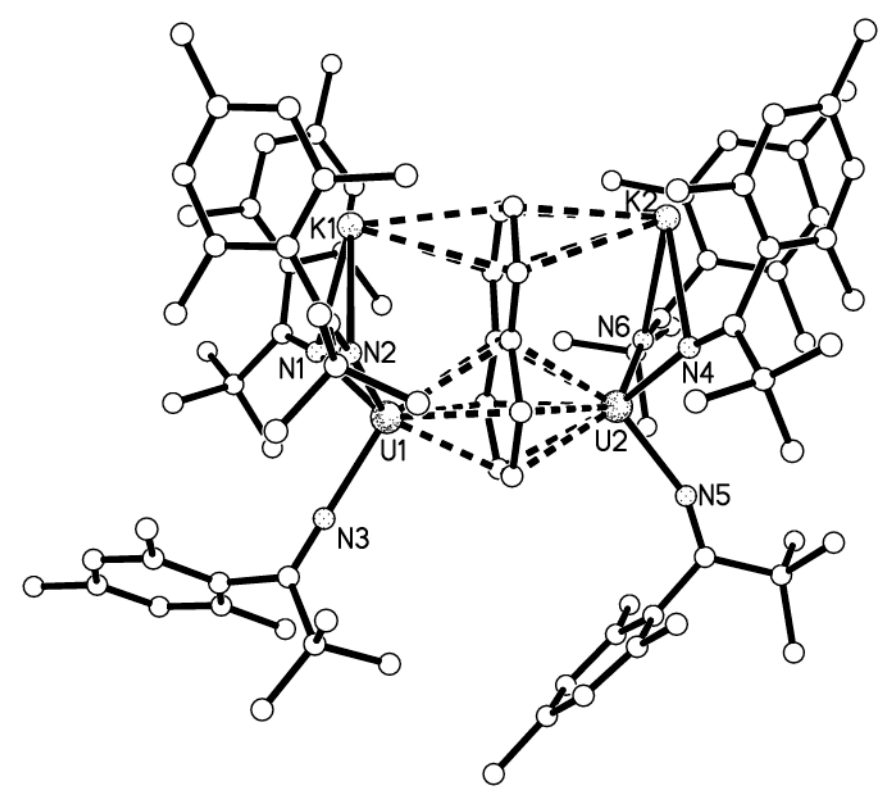

Figure 5. Molecular structure of 9a with selective labelling and hydrogen atoms and $\mathrm{K} \cdots \mathrm{C}_{\text {Mesityl }}$ interactions omitted for clarity [37]. 


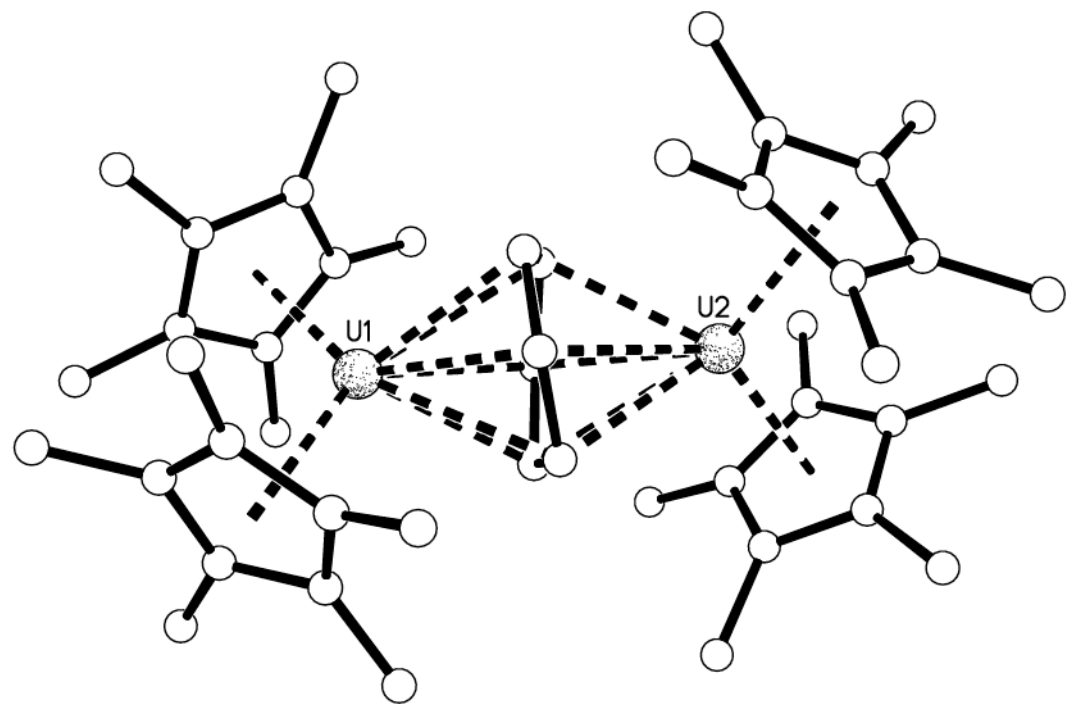

Figure 6. Molecular structure of $\mathbf{1 0}$ with selective labelling and hydrogen atoms omitted for clarity [38].

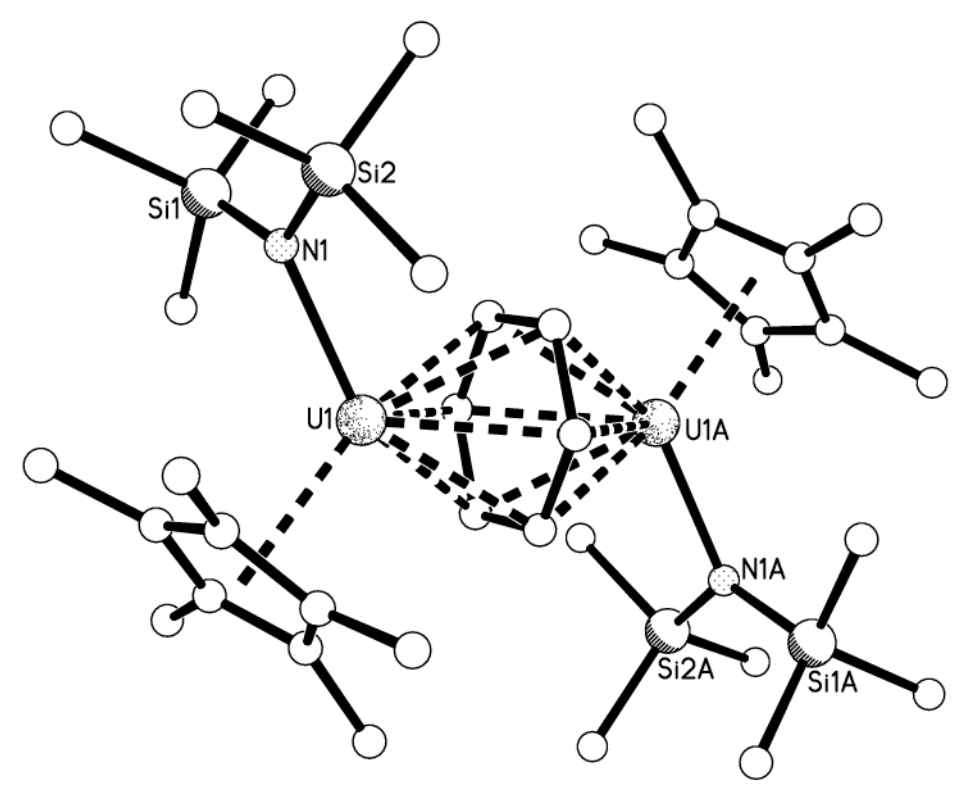

Figure 7. Molecular structure of $\mathbf{1 1}$ with selective labelling and hydrogen atoms omitted for clarity [38]. 


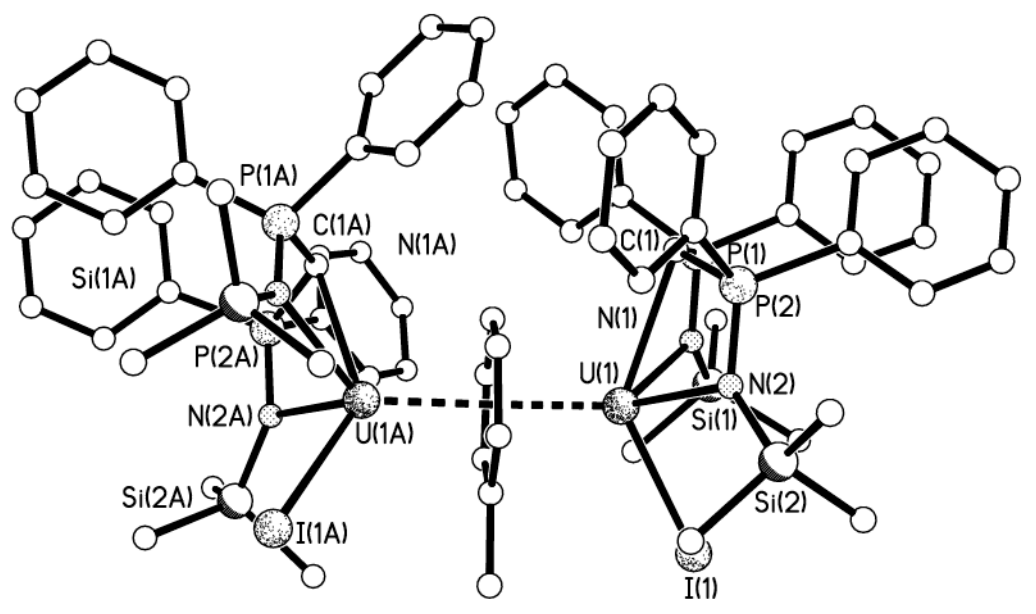

Figure 8. Molecular structure of $\mathbf{2 4}$ with selective labelling and hydrogen atoms omitted for clarity [40].

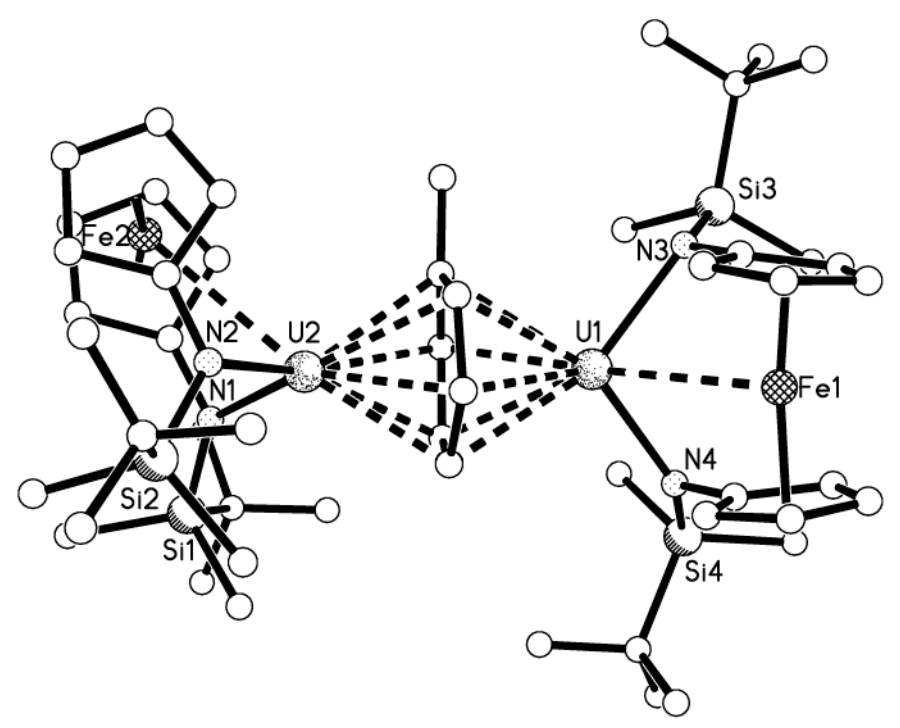

Figure 9. Molecular structure of 25 with selective labelling and hydrogen atoms omitted for clarity [43]. 


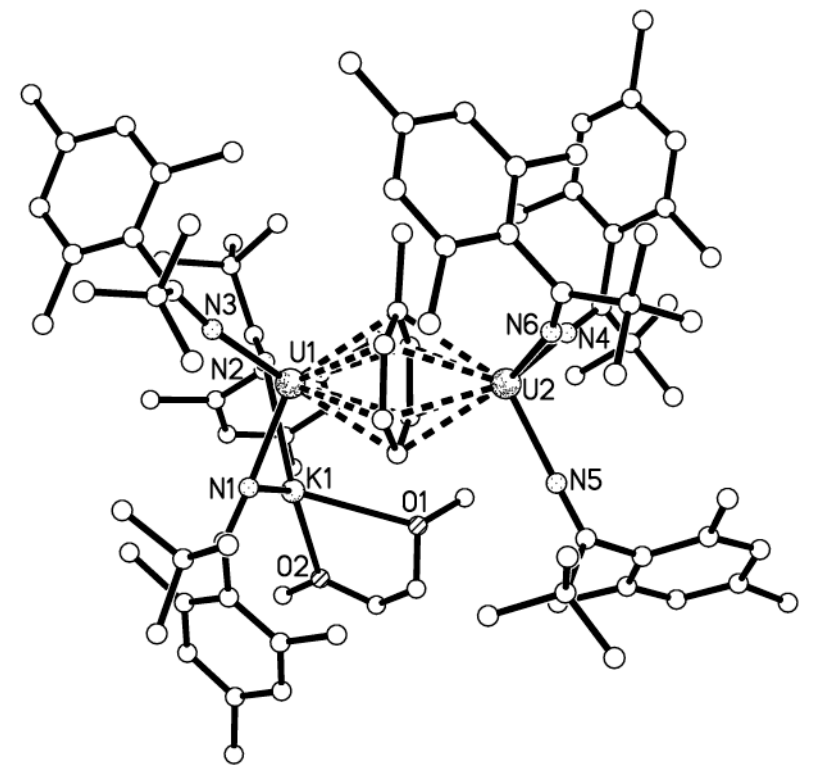

Figure 10. Molecular structure of 31.DME with selective labelling and hydrogen atoms and $\mathrm{K} \cdots \mathrm{C}_{\text {Mesityl }}$ interactions omitted for clarity [44].

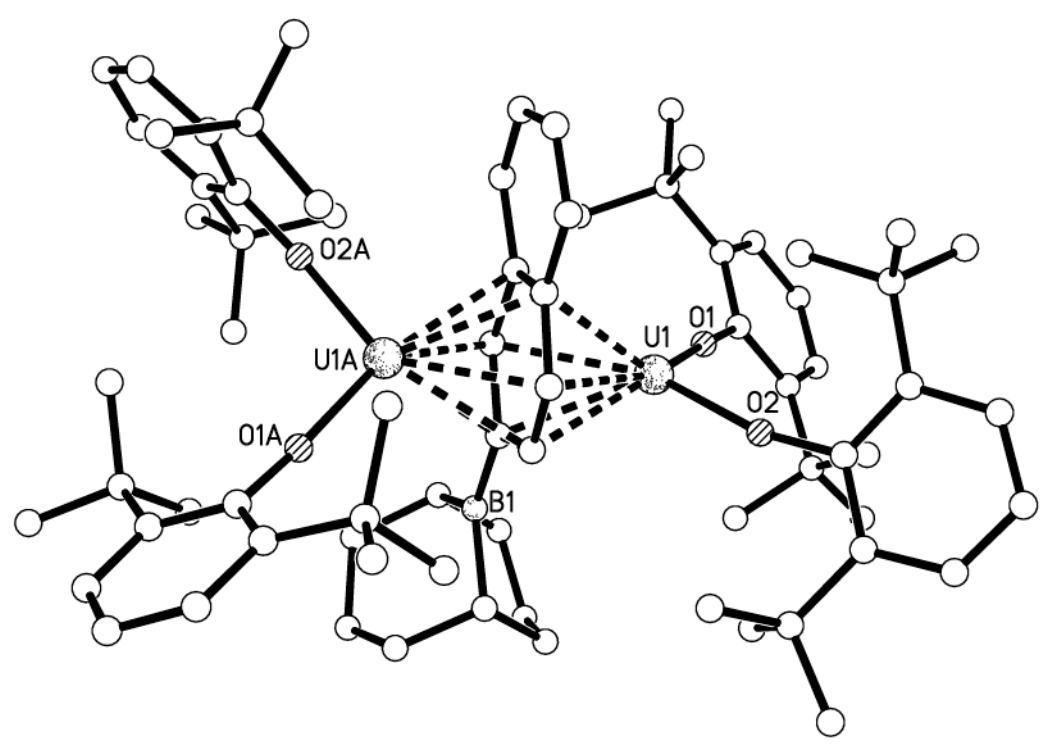

Figure 11. Molecular structure of 42 with selective labelling and hydrogen atoms omitted for clarity [45]. 


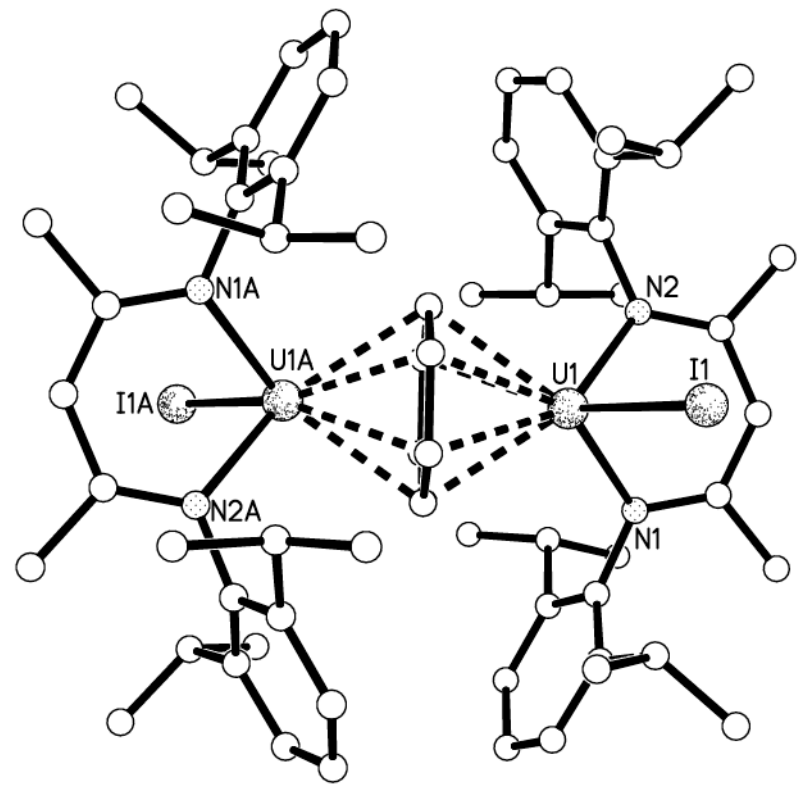

Figure 12. Molecular structure of $\mathbf{4 4}$ with selective labelling and hydrogen atoms omitted for clarity [47].

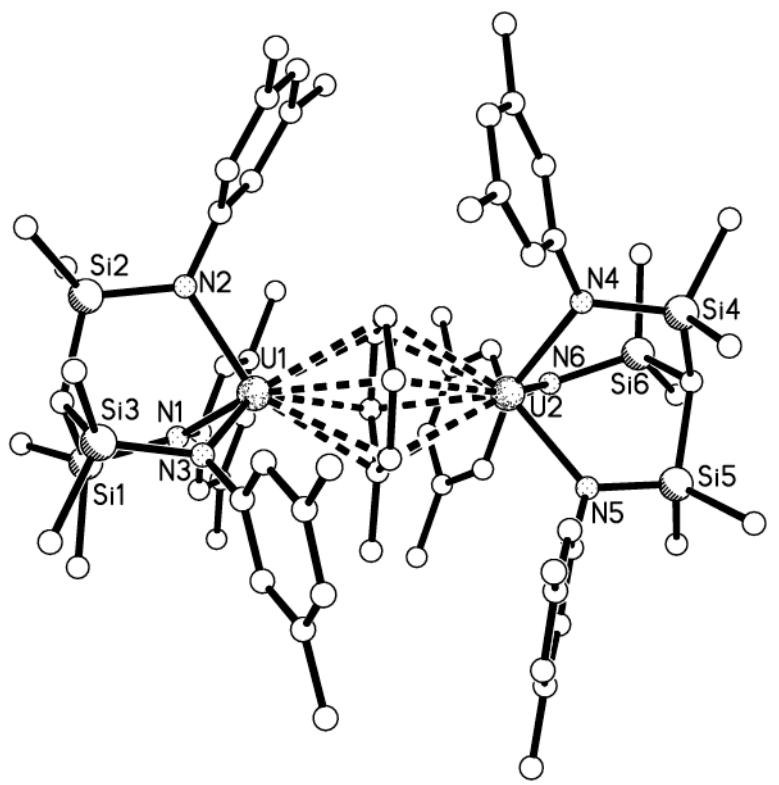

Figure 13. Molecular structure of $\mathbf{1}$ with selective labelling and hydrogen atoms omitted for clarity [18]. 


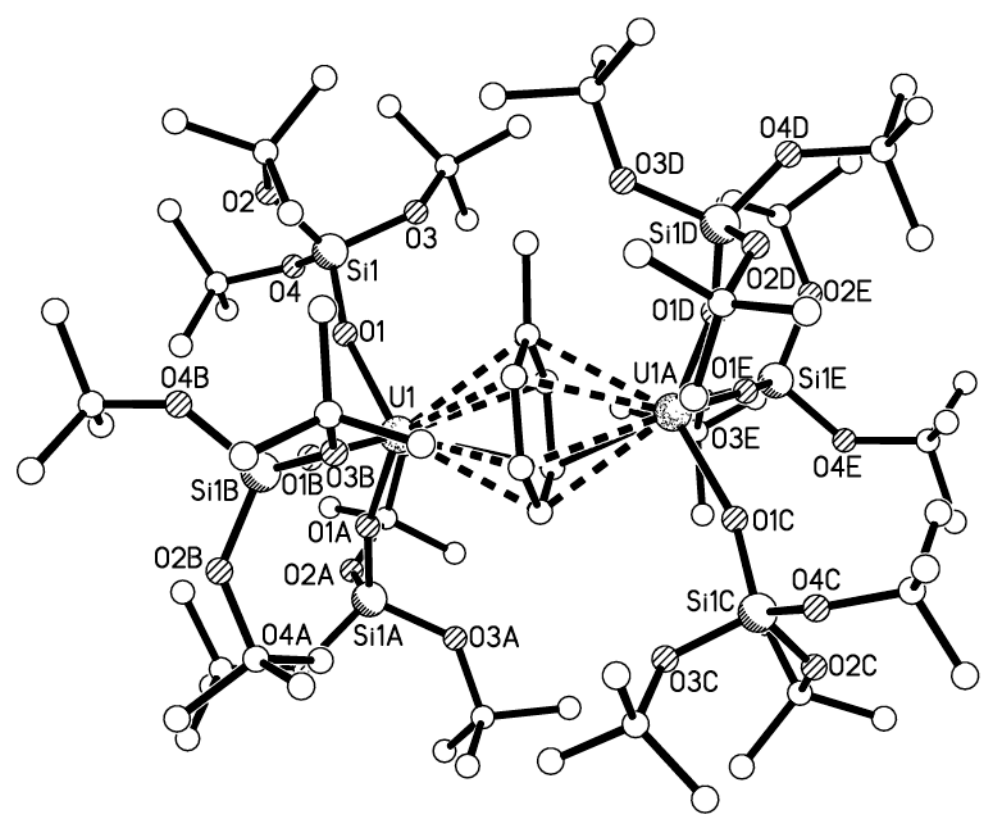

Figure 14. Molecular structure of 45 with selective labelling and hydrogen atoms omitted for clarity [50].

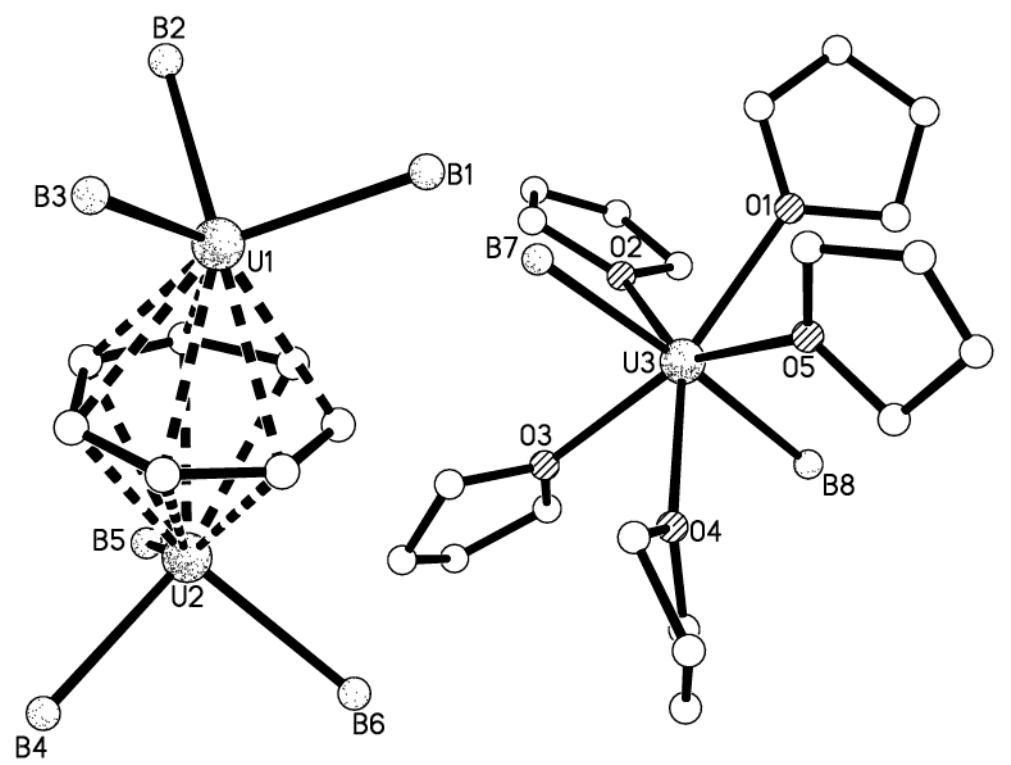

Figure 15. Molecular structure of $\mathbf{4 8}$ with selective labelling and hydrogen atoms omitted for clarity [54]. 


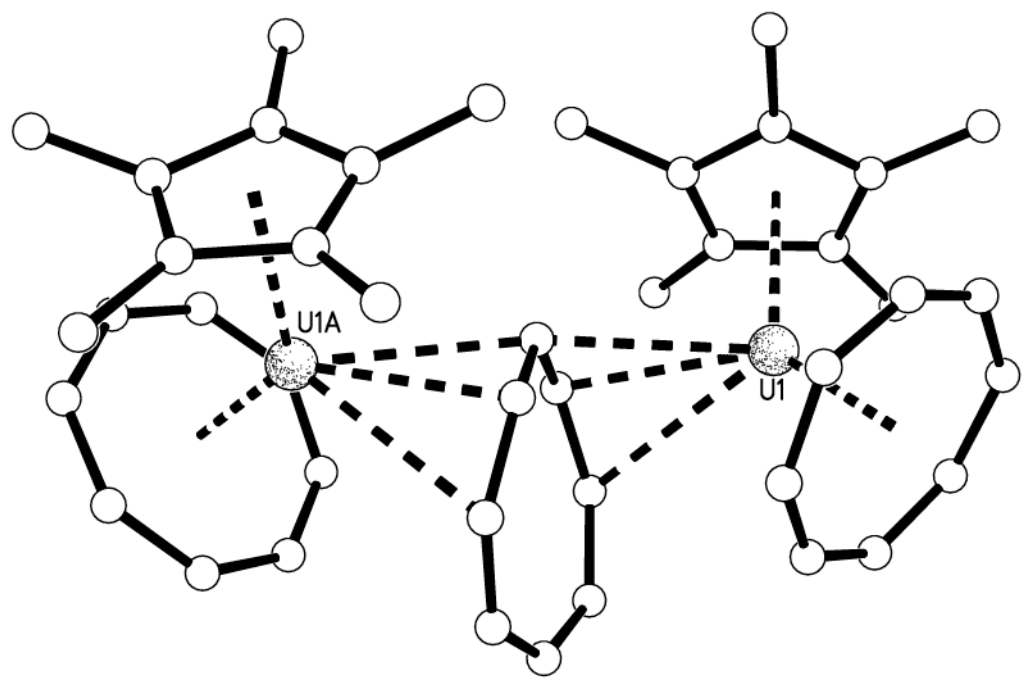

Figure 16. Molecular structure of $\mathbf{5 0}$ with selective labelling and hydrogen atoms omitted for clarity [56].

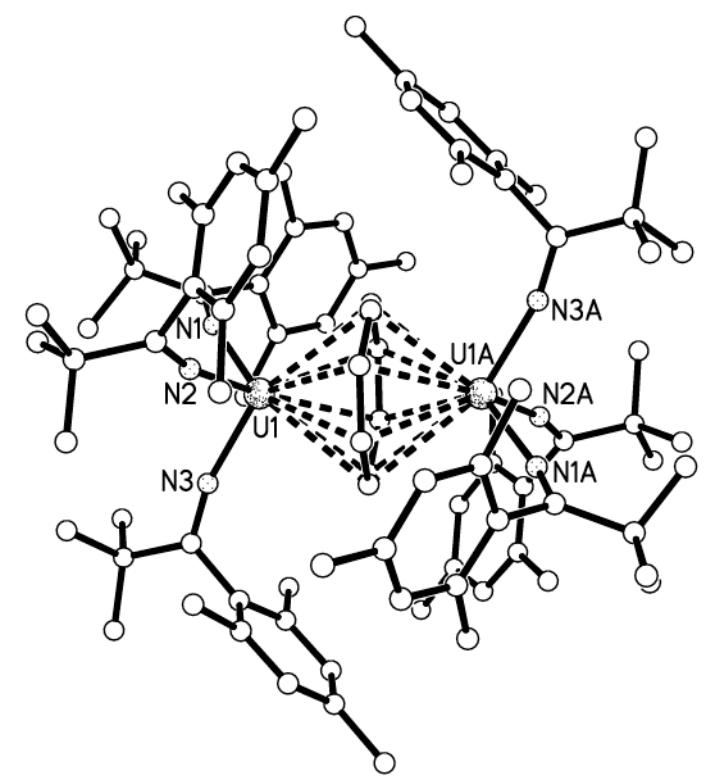

Figure 17. Molecular structure of $\mathbf{5 2}$ with selective labelling and hydrogen atoms omitted for clarity [37]. 

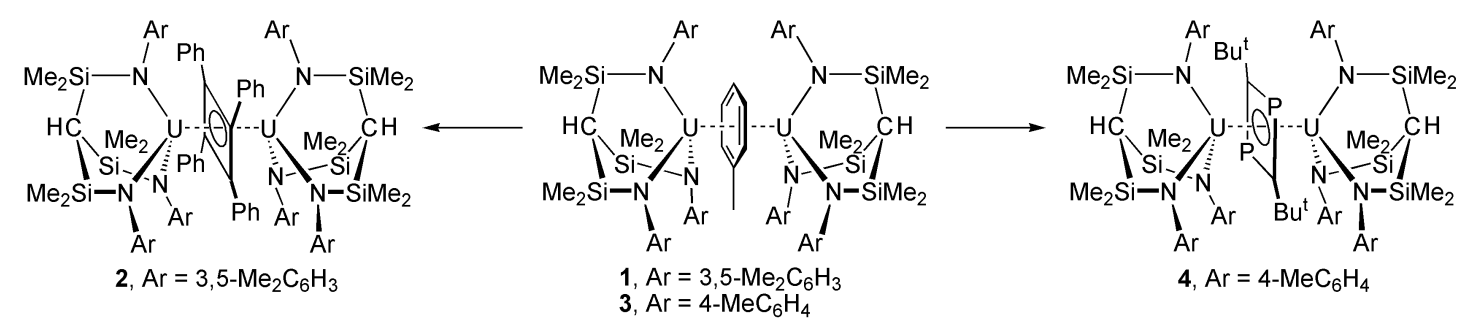

Scheme 1. Synthesis of 2 and 4 [17].

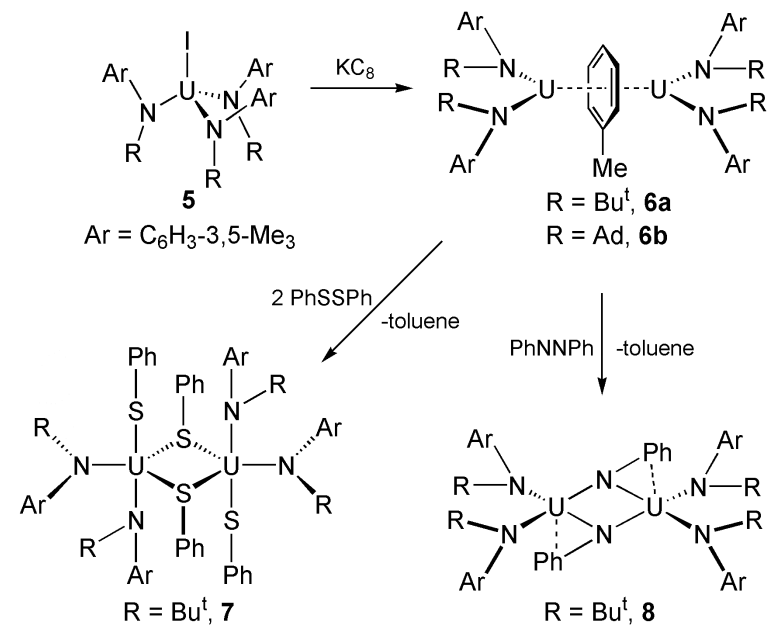

Scheme 2. Synthesis of 6a, 6b, 7, and 8 [36].
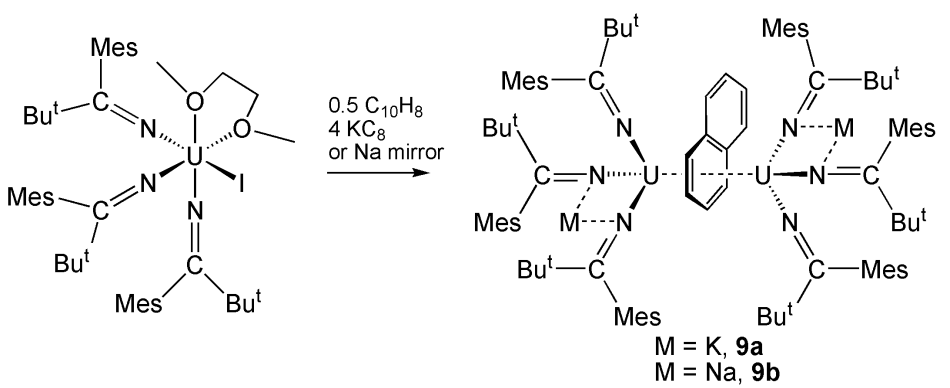

Scheme 3. Synthesis of $9 a$ and $9 b$ [37]. 


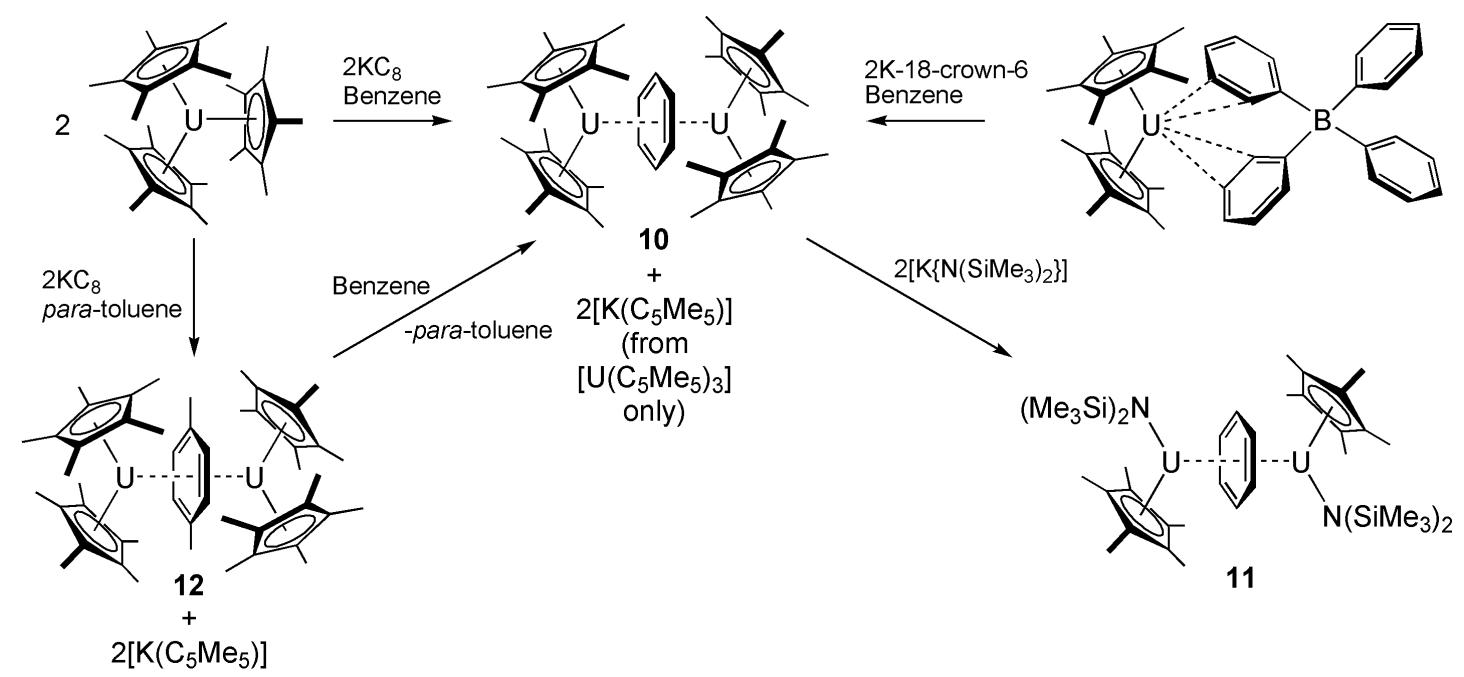

Scheme 4. Synthesis of 10-12 [38].

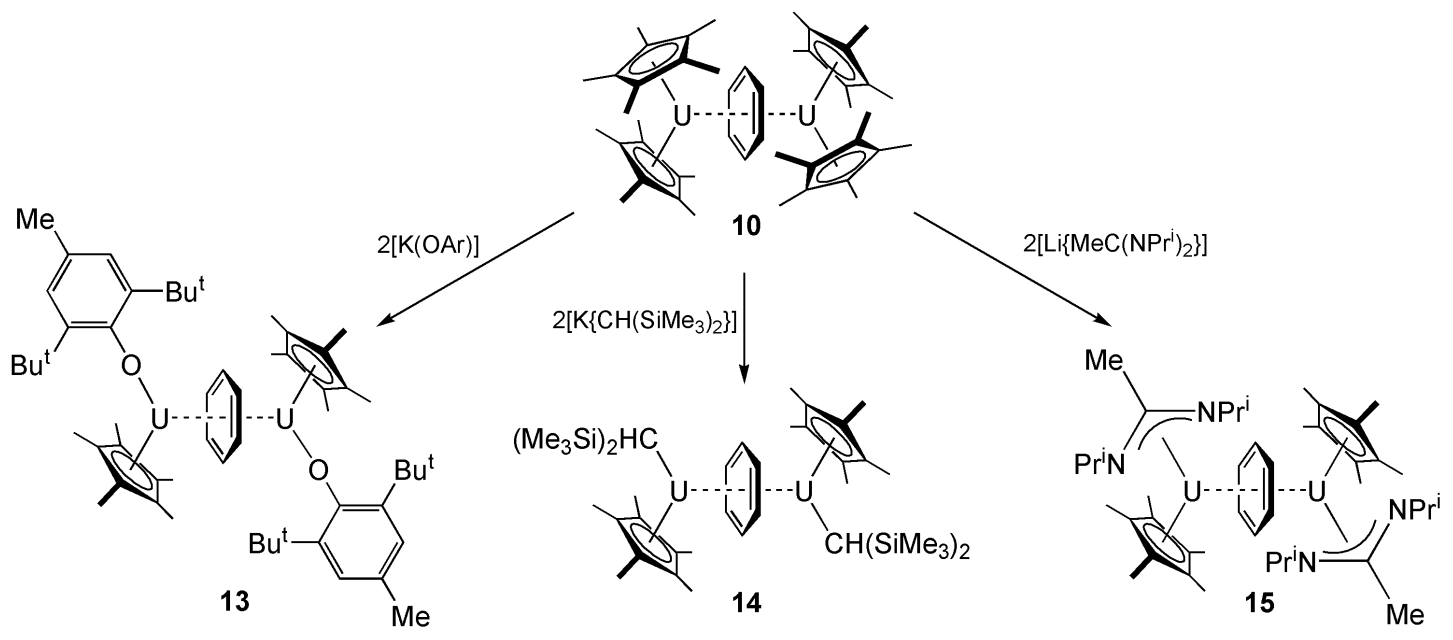

Scheme 5. Synthesis of 13-15 [39].

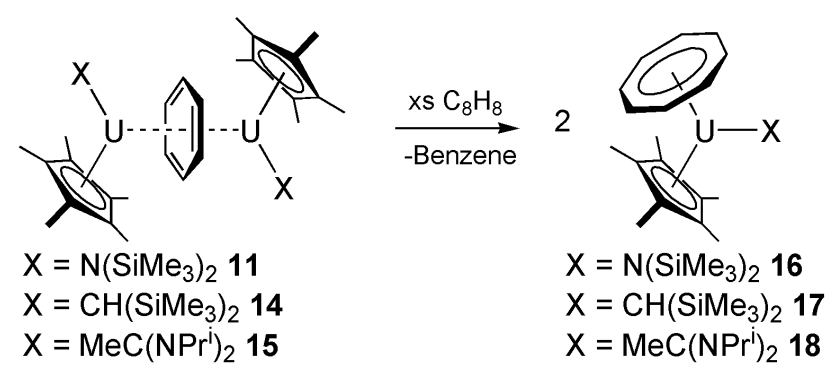

Scheme 6. Synthesis of 16-18 [39]. 


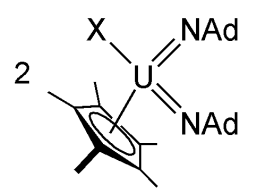

$\mathrm{X}=\mathrm{N}\left(\mathrm{SiMe}_{3}\right)_{2} 20$

(from 11)

$\mathrm{X}=\mathrm{MeC}\left(\mathrm{NPr}^{\mathrm{j}}\right)_{2} 21$

(from 15)
$+10 \% 19 \frac{4 \mathrm{AdN}_{3}}{- \text { Benzene }}$ Benzene

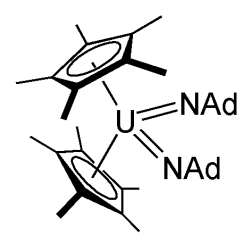

19
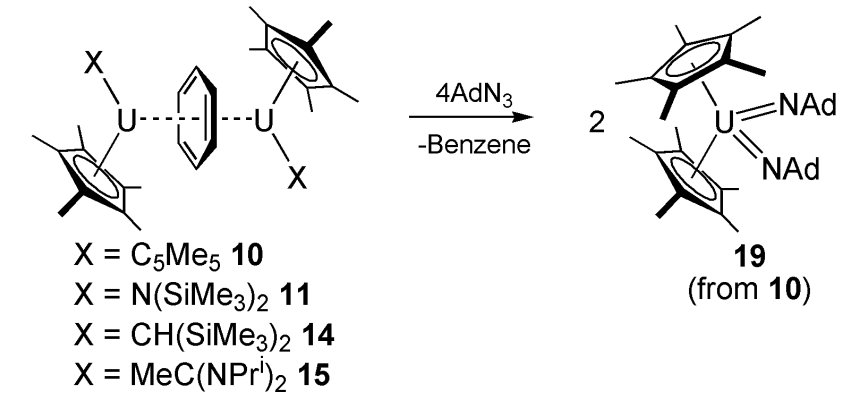

(from 10)

$$
4 \mathrm{AdN}_{3} \downarrow \text {-Benzene }
$$

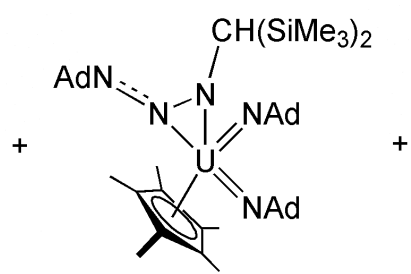

22

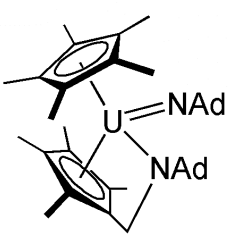

23

Scheme 7. Synthesis of 19, 20-23 [39].

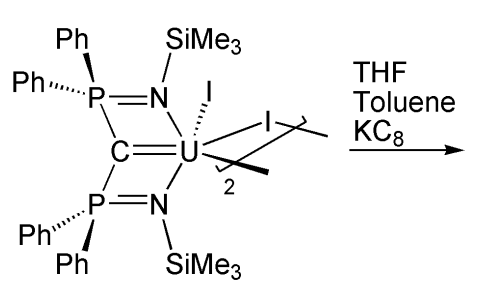

Scheme 8. Synthesis of 24 [40].

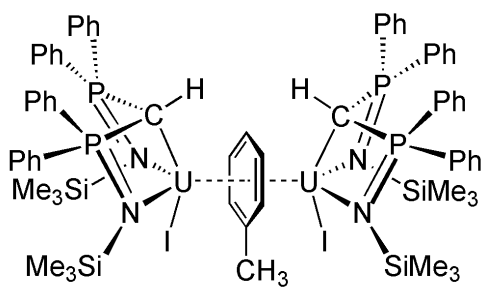

24 

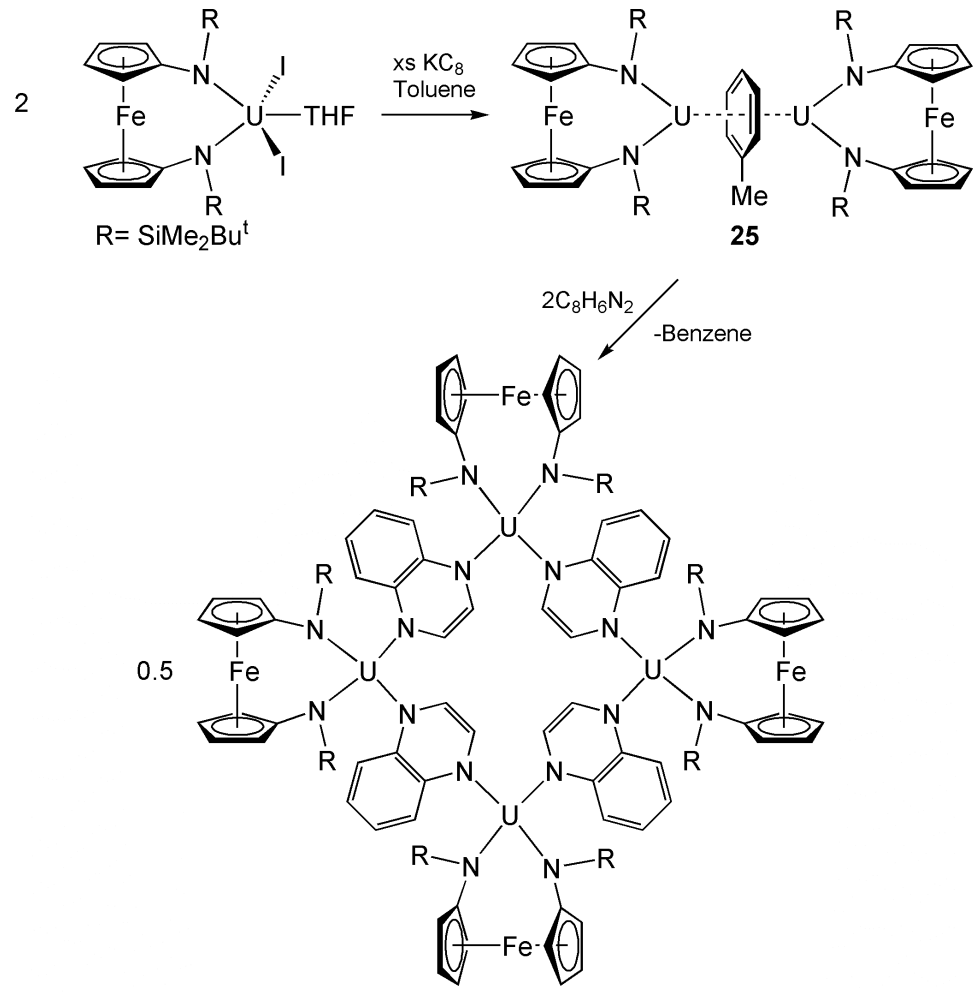

26

Scheme 9. Synthesis of 25 and 26 [43].
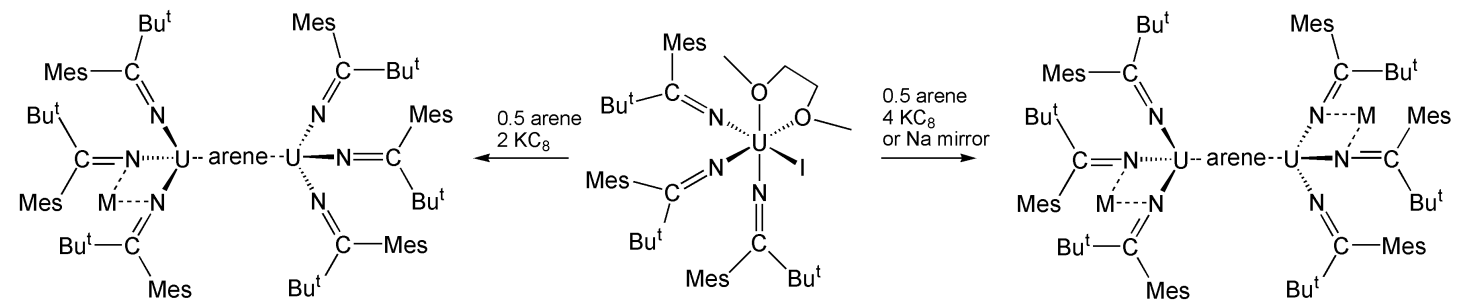

arene $=$ benzene 30

arene $=$ toluene 31

arene $=$ naphthalene 32

arene $=$ biphenyl 33

arene $=$ trans-stilbene 34

arene $=$ para-terphenyl $\mathbf{3 5}$

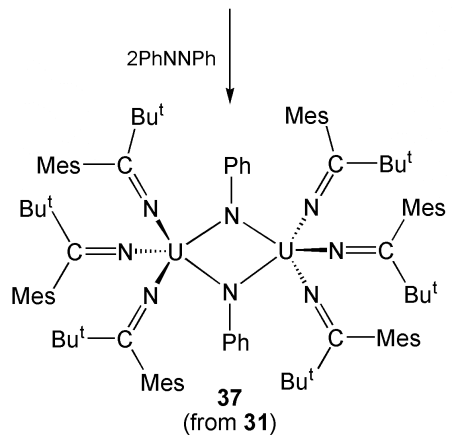

arene $=$ naphthalene $\mathrm{K} 9 \mathrm{a} \mathrm{Na} 9 \mathrm{~b}$

arene = biphenyl K 27a Na 27b

arene $=$ trans-stilbene $\mathrm{K} \mathbf{2 8 a ~ N a ~ 2 8 b}$

arene $=$ para-terphenyl K 29a Na 29b

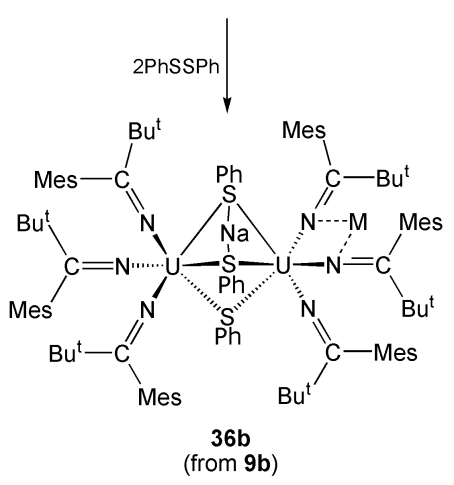

Scheme 10. Synthesis of 27a-29a, 27b-29b, and 30-35 [44]. 


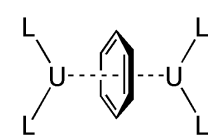

arene $=$ benzene, $\mathrm{L}=\mathrm{OC}_{6} \mathrm{H}_{2}-2,4,6-\mathrm{Bu}_{3}^{\mathrm{t}} 40 \mathrm{a}$

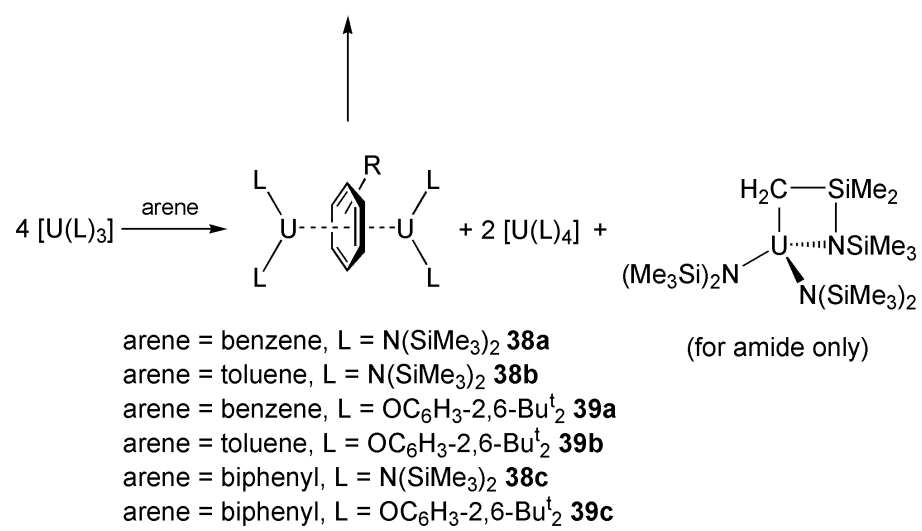

Scheme 11. Synthesis of 38a-38c, 39a-38c, and 40a [45].

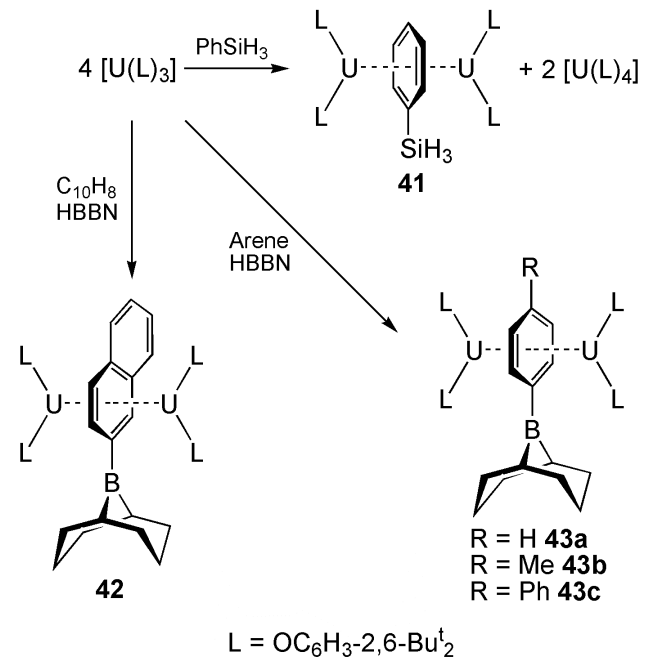

Scheme 12. Synthesis of 41, 42, and 43a-43c [45].

$$
\left[\mathrm{U}(\mathrm{L})(\mathrm{I})_{2}(\mathrm{THF})\right] \stackrel{\mathrm{KC}_{8}}{\longrightarrow}
$$

Scheme 13. Synthesis of 44 [47].

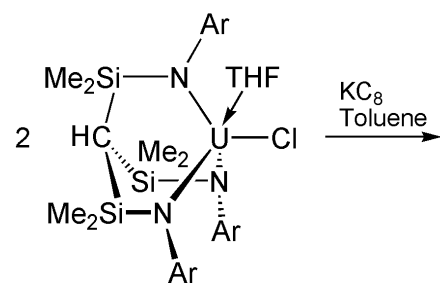

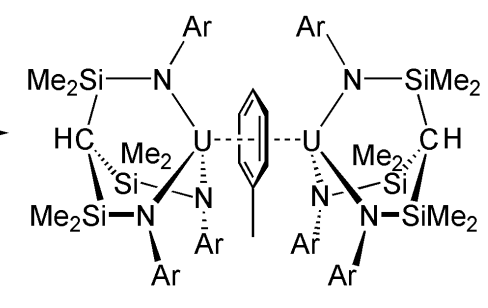

$\mathrm{Ar}=\mathrm{C}_{6} \mathrm{H}_{3}-3,5-\mathrm{Me}_{2} 1$

$\mathrm{Ar}=\mathrm{C}_{6} \mathrm{H}_{4}-4-\mathrm{Me} 3$ 
Scheme 14. Synthesis of 1 and 3 [18,19].
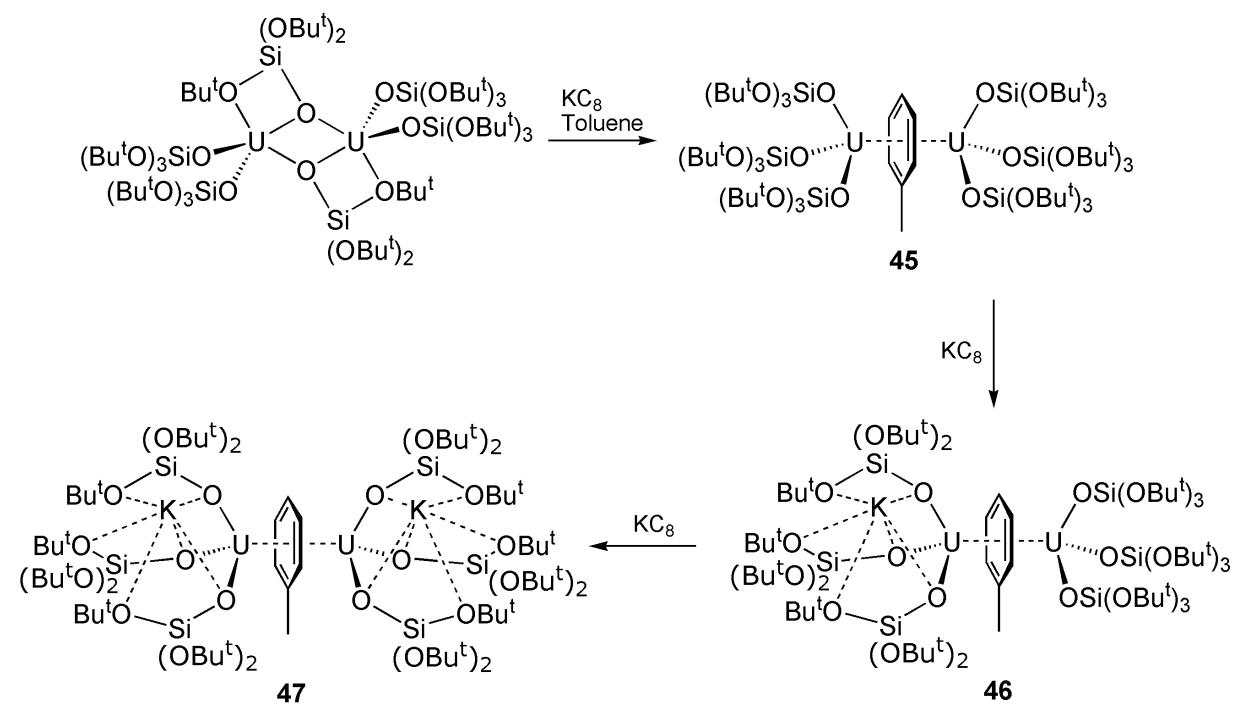

Scheme 15. Synthesis of 45-47 [50,51].

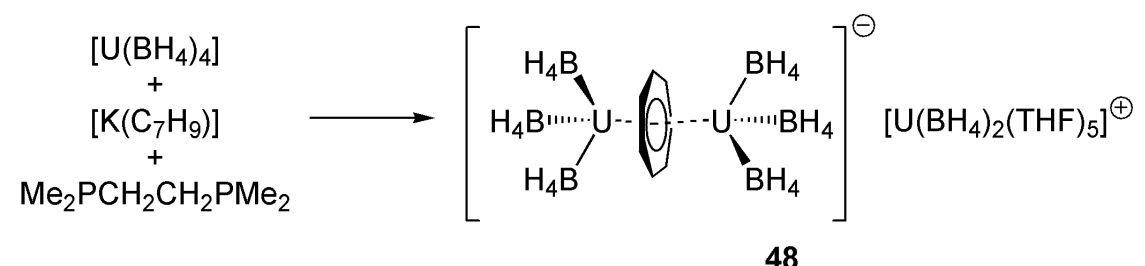

Scheme 16. Synthesis of 48 [54].
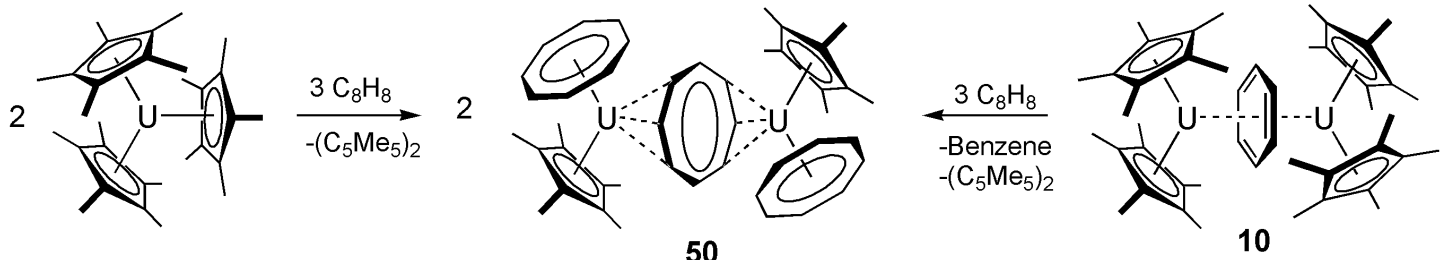

Scheme 17. Synthesis of $\mathbf{5 0}$ [56]. 

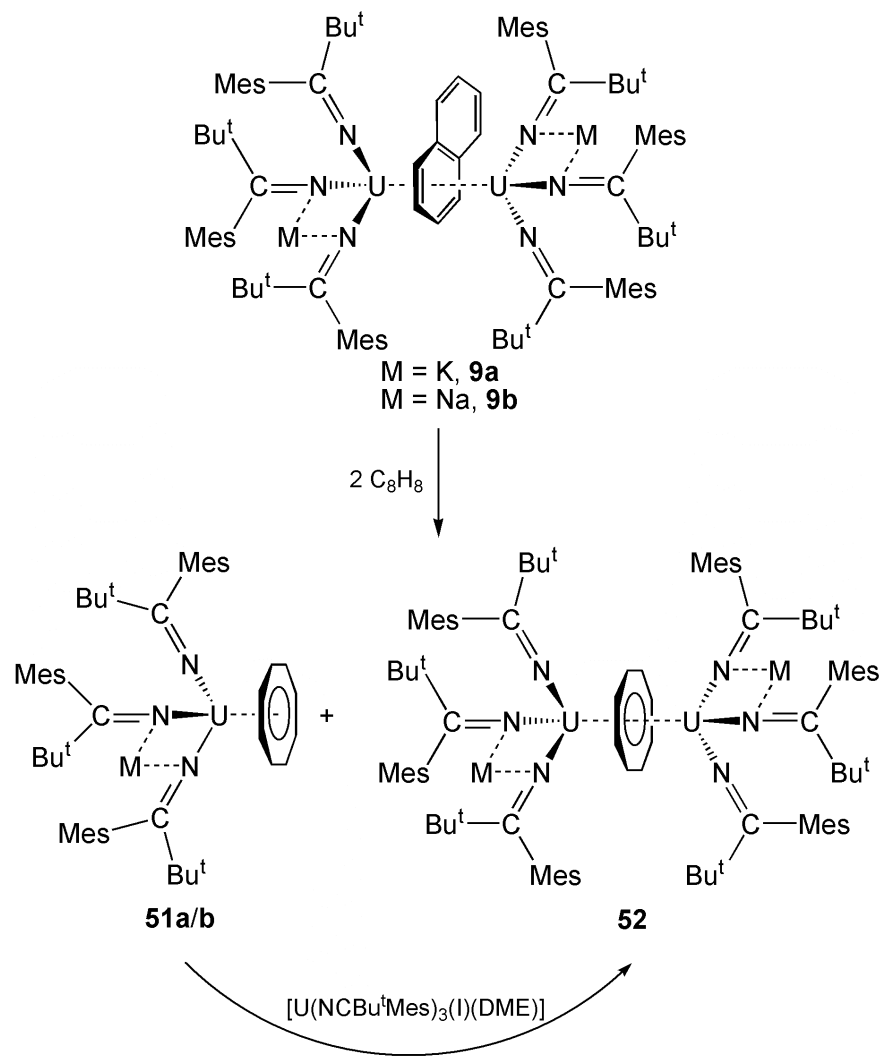

Scheme 18. Synthesis of 51a/b and 52 [37].

\section{ToC Entry}

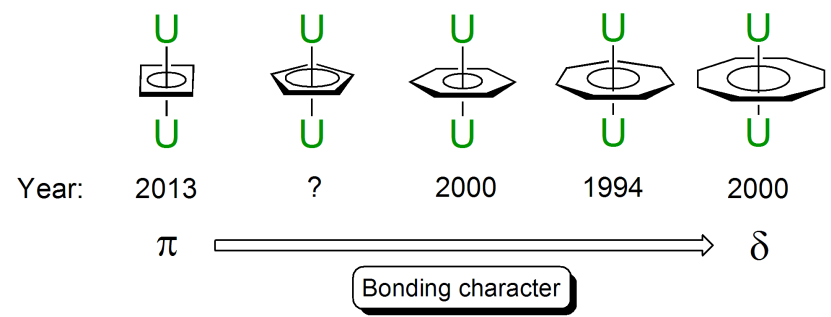

The chemistry of inverted sandwich aromatic arene complexes of uranium is reviewed.

\section{Highlights}

- Cyclobutadienyl complexes of uranium reviewed.

- Absence of cyclopentadienyl complexes of uranium noted.

- Arene complexes of uranium reviewed.

- Cycloheptatrienyl complexes of uranium reviewed.

- Cyclooctatetraenyl complexes of uranium reviewed. 